TITLE:

\title{
Xk-Related Protein 8 and CED-8 Promote Phosphatidylserine Exposure in Apoptotic Cells
}

$\operatorname{AUTHOR}(S)$ :

Suzuki, Jun; Denning, Daniel P; Imanishi, Eiichi; Horvitz, H Robert; Nagata, Shigekazu

CITATION:

Suzuki, Jun ...[et al]. Xk-Related Protein 8 and CED-8 Promote Phosphatidylserine Exposure in Apoptotic Cells. Science 2013, 341(6144): 403-406

ISSUE DATE:

2013-07-11

URL:

http://hdl.handle.net/2433/176304

\section{RIGHT:}

(c) 2013 American Association for the Advancement of Science.: This is the author's version of the work. It is posted here by permission of the AAAS for personal use, not for redistribution. The definitive version was published in Science on July 11 2013, DOI: 10.1126/science.1236758; この論文は出版社版でありません。引用の際には出版社版をご確認ご利 用ください。; This is not the published version. Please cite only the published version. 


\title{
Title: Xk-related protein 8 and CED-8 promote phosphatidylserine exposure in apoptotic cells
}

\author{
Authors: Jun Suzuki ${ }^{1}$, Daniel P. Denning ${ }^{2}$, Eiichi Imanishi ${ }^{1}$, H. Robert Horvitz ${ }^{2}$, and \\ Shigekazu Nagata ${ }^{1,3, *}$
}

\begin{abstract}
Affiliations:
${ }^{1}$ Department of Medical Chemistry, Graduate School of Medicine, Kyoto University, Yoshida-Konoe, Sakyo-ku, Kyoto, Kyoto 606-8501, Japan.

${ }^{2}$ Howard Hughes Medical Institute and Department of Biology, Massachusetts Institute of Technology, Cambridge, Massachusetts 02139, USA.

${ }^{3}$ Core Research for Evolutional Science and Technology, Japan Science and Technology Corporation, Yoshida-Konoe, Sakyo, Kyoto 606-8501, Japan.

*Correspondence to: E-mail: snagata@mfour.med.kyoto-u.ac.jp.

A classic feature of apoptotic cells is the cell-surface exposure of phosphatidylserine (PtdSer) as an "eat me" signal for engulfment. We show that the Xk-family protein Xkr8 mediates PtdSer exposure in response to apoptotic stimuli. Mouse $\mathrm{Xkr} 8^{-/}$cells or human cancer cells in which Xkr8 expression was repressed by hypermethylation failed to expose PtdSer during apoptosis and were inefficiently engulfed by phagocytes. Xkr8 was activated directly by caspases and required a caspase-3 cleavage site for its function. CED-8, the only Caenorhabditis elegans Xk-family homolog, also promoted apoptotic PtdSer exposure and cell-corpse engulfment. Thus, Xk-family proteins have evolutionarily conserved roles in promoting the phagocytosis of dying cells by altering the phospholipid distribution in the plasma membrane.
\end{abstract}

One Sentence Summary: Xkr-family transmembrane proteins mediate the externalization of phosphatidylserine, a signal that triggers the engulfment of apoptotic cells. 
Phospholipids are distributed asymmetrically between the outer and inner leaflets of plasma membranes (1): PtdSer and phosphatidylethanolamine (PtdEtn) localize exclusively to the inner leaflet, whereas $60-70 \%$ of phosphatidylcholine (PtdCho) and sphingomyelin (SM) are found on the outer leaflet. This asymmetric distribution is disrupted during apoptosis, and exposed PtdSer on dying cells serves as an "eat me" signal to facilitate phagocytosis $(2,3)$. PtdSer exposure and the more general transfer of phospholipids between the inner and outer leaflets are likely mediated by phospholipid scramblases (1), the identities of which are disputed (4).

We previously generated a mouse $\mathrm{Ba} / \mathrm{F} 3$ pro-B cell line (Ba/F3-PS19) with a high level of PtdSer exposure, constructed a cDNA library (of clones $>2.5 \mathrm{~kb}$ ) and discovered TMEM16F, a transmembrane protein required for $\mathrm{Ca}^{2+}$-dependent phospholipid scrambling but not apoptosis-dependent PtdSer exposure $(5,6)$. To identify molecules that mediate apoptotic PtdSer exposure, we introduced a Ba/F3-PS19 cDNA library (of clones 1.0-2.5 kb) into $\mathrm{Ba} / \mathrm{F} 3$ cells, serially enriched for cells with high PtdSer exposure, and established a cell line (LD-PS5-2-2) with a high level of PtdSer exposure (Fig. 1A). LD-PS5-2-2 cells carried a cDNA encoding Xkr8, a member of the evolutionarily conserved XK protein family (7) (figs. $\mathrm{S} 1$ and S2). Analyses of the amino acid sequences of vertebrate Xkr8 orthologs using the programs Transmembrane Prediction (TMpred; www.ch.embnet.org) and Transmembrane Hidden Markov Model (TMHMM; www.cbs.dtu.dk) suggested that Xkr8 contains six transmembrane regions flanked by cytosolic N- and C-termini (fig. S3).

We transformed mouse T cell lymphoma WR19L cells with Fas (8) (WR-Fas). Fas ligand (FasL) efficiently induced apoptosis of the WR-Fas cells, accompanied by caspase-3 activation and PtdSer exposure (Fig. 1B, and fig. S4). The introduction of mouse Xkr8-GFP (mXkr8 fused to green fluorescent protein) but not mTMEM16F-GFP increased the fraction of PtdSer-exposing cells generated by FasL (Fig. 1B). The expression of $\mathrm{m} X k r 8$ short hairpin RNAs (shRNA) in WR-Fas cells decreased the amount of the endogenous $\mathrm{m} X k r 8 \mathrm{mRNA}$ by $76-82 \%$ (fig. S5) and the fraction of cells with FasL-induced PdtSer-exposure (Fig. 1C) but not levels of caspase-3 activation (fig. S5). The transformation of $\mathrm{mXk} r 8$ shRNA-expressing cells with human (h) $X k r 8 \mathrm{cDNA}$, which is not recognized by the $\mathrm{m} X k r 8$ shRNAs, restored FasL-induced PdtSer exposure. hXkr8-GFP expressed in human 293T cells localized primarily to the plasma membrane (Fig. 1D), suggesting that Xkr8 functions at the cell surface to promote apoptotic PtdSer exposure.

Human PLB-985 leukemia and Raji lymphoma cells do not expose PtdSer during apoptosis $(9,10)$. Real-time RT-PCR indicated that the amount of $X k r 8 \mathrm{mRNA}$ in PLB-985 and Raji cells were $8 \%$ and 9\%, respectively, of those in Namalwa cells (Fig. 2A). PLB-985 or Raji cell transformants expressing $\mathrm{hXkr8}$ responded to apoptotic stimuli by exposing PtdSer (Fig. 2B). PtdSer exposure is necessary for the recognition of apoptotic cells by phagocytes $(3,10,11)$. Accordingly, whereas apoptotic PLB-985 cells were rarely engulfed by macrophages, their Xkr8 transformants were frequently internalized (Fig. 2C). Caspase-3 activation, DNA fragmentation, cell death, and cell shrinkage occurred similarly in PLB-985 cells with or without Xkr8-expression, indicating that Xkr8 and PtdSer exposure had no obvious effects on other aspects of the apoptotic process (fig. S6). The program "CpG island searcher" (www.cpgislands.usc.edu) identified two CpG islands near the transcription start site of the $\mathrm{hXkr8}$ gene (fig. S7). Bisulfite DNA sequencing (12) indicated that none of the 23 
CpGs between -232 and +4 of $\mathrm{h} X k r 8$ gene was methylated in peripheral blood leukocyte (PBL), Jurkat or Namalwa cells (fig. S7). By contrast, these CpGs were methylated with more than 90\% probability in PLB-985 and Raji cells. Treatment of PLB-985 cells with 5aza-2'-deoxycytidine (DAC) increased $X k r 8$ mRNA levels (Fig. 2D). After 7 days of DAC treatment, all CpGs were demethylated (fig. S7), and $X k r 8$ mRNA levels were $91 \%$ of that in Namalwa cells. Accordingly, DAC-treated PLB-985 cells exposed PtdSer upon UV irradiation (Fig. 2E). We suggest that the methylation of $\mathrm{CpG}$ islands in the $X k r 8$ promoter in PLB-985 and Raji cells blocks $X k r 8$ gene expression and prevents apoptotic PtdSer exposure.

We assayed staurosporine-treated PLB-985 or Xkr8-expressing PLB-985 cells for PtdEtn exposure using RO09-0198, and for PtdCho and SM internalization using 1-oleoyl-2\{6-[(7-nitro-2-1,3-benzoxadiazol-4-yl)amino]hexanoyl\}-sn-glycero-3-phosphocholine (NBDPC) and NBD-sphingosine-1-phosphocholine (NBD-SM), respectively. Inhibitor of caspaseactivated DNase (ICAD) was cleaved equally well in PLB-985 and its hXkr8 transformants following staurosporine treatment (fig. S8). By contrast, apoptotic hXkr8-expressing cells (but not parental cells) stained with RO09-0918 and internalized NBD-PC and NBD-SM (fig. S8), indicating that Xkr8, like TMEM16F (5), promotes the scrambling of multiple lipid species. Unlike TMEM16F, Xkr8 had no effect on the $\mathrm{Ca}^{2+}$-induced exposure of PtdSer (fig. S9), suggesting distinct pathways control $\mathrm{Ca}^{2+}$-induced phospholipid scrambling and apoptosis-induced scrambling. These findings are consistent with reports that B-cell lines from Scott patients, who carry a null mutation in TMEM16F, respond to apoptotic stimuli by exposing PtdSer (13), and that mouse $\mathrm{Bak}^{-/} \mathrm{Bax}^{-/-}$platelets, which do not undergo apoptosis, expose PtdSer upon $\mathrm{Ca}^{2+}$ ionophore treatment (14).

An analysis of Xkr8 sequences from six vertebrates using the program CASVM (www.casbase.org) identified a conserved caspase 3-recognition site near the Xkr8 Cterminus (fig. S1). We generated a mutant version of $\mathrm{hXkr8}$ (2DA) in which the putative caspase-recognition sequence at position 355 was changed from PDQVDG to PAQVAG (fig. S3). PLB-985 cells expressing wild-type hXkr8-GFP exposed PtdSer in response to staurosporine (Fig. 3A), accompanied by the loss of a 52-kD hXkr8-GFP band on polyacrylamide gels and the appearance of a 29-kD band detected with anti-GFP antibodies (Fig. 3B). Following staurosporine treatment, hXkr8(2DA)-GFP failed to promote PtdSer exposure and was not proteolytically processed; ICAD was cleaved in cells expressing either the wild-type or 2DA mutant of hXkr8, indicating similar caspase-3 activity in both cell lines. Processing of $\mathrm{mXkr8-GFP}$ at the caspase-recognition site during apoptosis was also observed in WR-Fas cells after treatment with FasL (Fig. 3C). The solubilized membrane fraction from cells expressing hXkr8-GFP was then incubated with human caspases. Western blot analysis with anti-GFP showed that caspases-3 and 7 cleaved the wild-type but not 2DA mutant $\mathrm{hXkr8}$ (Fig. 3D). Thus, mammalian Xkr8 is activated to expose PtdSer via caspase-mediated cleavage of its cytosolic C-terminus.

mXkr8 mRNA was detectable in most mouse tissues (fig. S10), with notably high

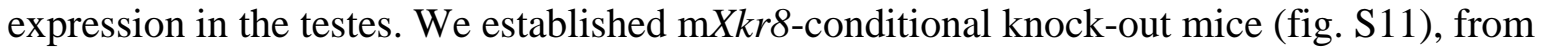
which we prepared mouse embryonic fibroblasts (MEF). After treatment with staurosporine,

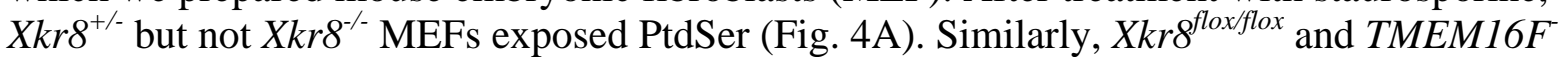
${ }^{1-}$ but not $\mathrm{Xkr}^{-/-}$fetal thymocyte (IFET) cell lines exposed PtdSer in response to FasL (Fig. 4B), although caspase-3 was activated similarly in these cell lines (fig. S12). The transformation of $\mathrm{Xkr}^{-/-}$IFETs with $\mathrm{mXkr8}$ restored PtdSer exposure in response to FasL. 
CED-8 is the only C. elegans homolog of Xk proteins and was previously shown to control the timing of programmed cell deaths (15) (fig. S2). To determine if CED-8 (like $\mathrm{Xkr8}$ ) promotes phagocytosis, we examined ced-8 eggs for "floater" cells, which are generated in embryos defective in engulfment; floaters are a subset of apoptotic cells that if not engulfed (e.g., in ced $-1,-2,-5,-6,-7,-10$ or -12 mutants) detach from the embryo (Fig. $4 \mathrm{C}$; fig. S13) $(16,17)$. ced-8 eggs contained floaters, and ced-8 mutations synergistically enhanced the number of floaters in engulfment mutants. This enhancement was dependent on the caspase gene ced-3 (fig. S14), which is required for apoptosis partially defective in engulfment. The PtdSer-binding protein MFG-e8::Venus (18) associated with $94 \%$ of apoptotic cell corpses in the ventral cords of wild-type animals but only with $21 \%$ of those in ced-8 mutants (Fig. 4D). Similarly, PtdSer was exposed on newly detached floaters from ced1 but not ced-8 or $c e d-1$; ced-8 embryos (fig. S15). Since $21 \%$ of ced-8 ventral cord cell corpses have normal PtdSer exposure, additional factors likely contribute to this process.

In short, the Xk-related proteins Xkr8 and CED-8 promote caspase-dependent PtdSer exposure during apoptosis. Based on the following observations, Xkr8 and CED-8 likely act at a late step in PtdSer exposure, possibly in phospholipid scrambling: i) $\mathrm{Xkr} 8$-deficient cells expose PtdSer in response to $\mathrm{Ca}^{2+}$, indicating $\mathrm{Xkr} 8$ is dispensable for steps prior to PtdSer exposure, including PtdSer biogenesis and localization; ii) Xkr8 is directly activated by caspase cleavage, suggesting Xkr8 does not function prior to the onset of apoptosis; and iii) Xkr8 and CED-8 are transmembrane proteins at the plasma membrane and therefore positioned to effect -- or interact with partners that effect -- the externalization of PtdSer during apoptosis.

Although intracellular concentrations of $\mathrm{Ca}^{2+}$ increase during apoptosis $(19,20)$, the involvement of $\mathrm{Ca}^{2+}$ in apoptotic PtdSer exposure is unclear (4) and our observations do not support a generalization. We found that FasL-induced PtdSer exposure was $\mathrm{Ca}^{2+}$-dependent in WR19L but not Ba/F3 cells and that when WR19L cells were transformed with Xkr8, they lost the $\mathrm{Ca}^{2+}$ requirement for the apoptotic exposure of PtdSer. These results, together with the constitutive activity of overexpressed $\mathrm{Xkr} 8$ in $\mathrm{Ba} / \mathrm{F} 3$ but not other cells, suggest that $\mathrm{Xkr} 8$ might cooperate with $\mathrm{Ca}^{2+}$-regulated proteins in some cell-specific contexts.

The swift clearance of dead cells is essential for maintaining homeostasis, and the masking of PtdSer on apoptotic cells or the failure of the engulfment system can cause autoimmune disorders like systemic lupus erythematosus $(3,21)$. Our finding that in cancer cells $\mathrm{Xkr8}$ is epigenetically repressed suggests a mechanistic link among inflammation, autoimmunity and cancer (22).

\section{References and Notes:}

1. P. A. Leventis, S. Grinstein, The distribution and function of phosphatidylserine in cellular membranes. Annu. Rev. Biophys. 39, 407-427 (2010). doi:10.1146/annurev.biophys.093008.131234

2. K. S. Ravichandran, U. Lorenz, Engulfment of apoptotic cells: signals for a good meal. Nat. Rev. Immunol. 7, 964-974 (2007). doi:10.1038/nri2214

3. S. Nagata, R. Hanayama, K. Kawane, Autoimmunity and the clearance of dead cells. Cell 140, 619-630 (2010). doi:10.1016/j.cell.2010.02.014 
4. E. M. Bevers, P. L. Williamson, Phospholipid scramblase: an update. FEBS Lett 584, 2724-2730 (2010). doi:10.1016/j.febslet.2010.03.020

5. J. Suzuki, M. Umeda, P. J. Sims, S. Nagata, Calcium-dependent phospholipid scrambling by TMEM16F. Nature 468, 834-838 (2010). doi:10.1038/nature09583

6. J. Suzuki et al., Calcium-dependent phospholipid scramblase activity of TMEM16 family members. J. Biol. Chem. 288, 13305-13316 (2013). doi:10.1074/jbc.M113.457937

7. G. Calenda et al., Identification of two new members, XPLAC and XTES, of the XK family. Gene 370, 6-16 (2006). doi:10.1016/j.gene.2005.10.037

8. S. Nagata, Apoptosis by death factor. Cell 88, 355-365 (1997). doi:10.1016/S00928674(00)81874-7

9. $\quad$ B. Fadeel et al., Phosphatidylserine exposure during apoptosis is a cell-type-specific event and does not correlate with plasma membrane phospholipid scramblase expression. Biochem. Biophys. Res. Commun. 266, 504-511 (1999). doi:10.1006/bbrc.1999.1820

10. V. A. Fadok et al., Loss of phospholipid asymmetry and surface exposure of phosphatidylserine is required for phagocytosis of apoptotic cells by macrophages and fibroblasts. J. Biol. Chem. 276, 1071-1077 (2001). doi:10.1074/jbc.M003649200

11. R. Hanayama et al., Identification of a factor that links apoptotic cells to phagocytes. Nature 417, 182-187 (2002). doi:10.1038/417182a

12. J. G. Herman et al., Methylation-specific PCR: a novel PCR assay for methylation status of CpG islands. Proc. Natl. Acad. Sci. USA 93, 9821-9826 (1996).

13. P. Williamson et al., Phospholipid scramblase activation pathways in lymphocytes. Biochemistry 40, 8065-8072 (2001). doi:10.1021/bi001929z

14. S. M. Schoenwaelder et al., Two distinct pathways regulate platelet phosphatidylserine exposure and procoagulant function. Blood 114, 663-666 (2009). doi:10.1182/blood-2009-01-200345

15. G. M. Stanfield, H. R. Horvitz, The ced-8 gene controls the timing of programmed cell deaths in C. elegans. Mol. Cell 5, 423-433 (2000). doi:10.1016/S10972765(00)80437-2

16. Y. C. Wu, G. M. Stanfield, H. R. Horvitz, NUC-1, a Caenorhabditis elegans DNase II homolog, functions in an intermediate step of DNA degradation during apoptosis. Genes Dev. 14, 536-548 (2000). doi:10.1101/gad.14.5.536

17. D. P. Denning, V. Hatch, H. R. Horvitz, Programmed elimination of cells by caspaseindependent cell extrusion in C. elegans. Nature 488, 226-230 (2012). doi:10.1038/nature11240

18. V. Venegas, Z. Zhou, Two alternative mechanisms that regulate the presentation of apoptotic cell engulfment signal in Caenorhabditis elegans. Mol. Biol. Cell 18, 31803192 (2007). doi:10.1091/mbc.E07-02-0138

19. D. L. Bratton et al., Appearance of phosphatidylserine on apoptotic cells requires calcium-mediated nonspecific flip-flop and is enhanced by loss of the 
aminophospholipid translocase. J. Biol. Chem. 272, 26159-26165 (1997). doi:10.1074/jbc.272.42.26159

20. M. B. Hampton, D. M. Vanags, M. I. Porn-Ares, S. Orrenius, Involvement of extracellular calcium in phosphatidylserine exposure during apoptosis. FEBS Lett. 399, 277-282 (1996). doi:10.1016/S0014-5793(96)01341-5

21. L. E. Munoz et al., The role of defective clearance of apoptotic cells in systemic autoimmunity. Nat. Rev. Rheumatol. 6, 280-289 (2010). doi:10.1038/nrrheum.2010.46

22. A. L. Franks, J. E. Slansky, Multiple associations between a broad spectrum of autoimmune diseases, chronic inflammatory diseases and cancer. Anticancer Res. 32, 1119-1136 (2012). doi:32/4/1119

23. J. Mapes et al., CED-1, CED-7, and TTR-52 regulate surface phosphatidylserine expression on apoptotic and phagocytic cells. Curr. Biol. 22, 1267-1275 (2012). doi:10.1016/j.cub.2012.05.052

24. Y. Zhang et al., C. elegans secreted lipid-binding protein NRF-5 mediates PS appearance on phagocytes for cell corpse engulfment. Curr. Biol. 22, 1276-1284 (2012). doi:10.1016/j.cub.2012.06.004

25. R. Palacios, M. Steinmetz, Il-3-dependent mouse clones that express B-220 surface antigen, contain Ig genes in germ-line configuration, and generate B lymphocytes in vivo. Cell 41, 727-734 (1985). doi:10.1016/S0092-8674(85)80053-2

26. K. A. Tucker, M. B. Lilly, L. Heck, T. A. Rado, Characterization of a new human diploid myeloid leukemia cell line (PLB-985) with granulocytic and monocytic differentiating capacity. Blood 70, 372-378 (1987).

27. S. Morita, T. Kojima, T. Kitamura, Plat-E: an efficient and stable system for transient packaging of retroviruses. Gene Ther. 7, 1063-1066 (2000).

28. R. Fukunaga, E. Ishizaka-Ikeda, S. Nagata, Purification and characterization of the receptor for murine granulocyte colony-stimulating factor. J. Biol. Chem. 265, 1400814015 (1990).

29. T. Shiraishi et al., Increased cytotoxicity of soluble Fas ligand by fusing isoleucine zipper motif. Biochem. Biophys. Res. Commun. 322, 197-202 (2004). doi:10.1016/j.bbrc.2004.07.098

30. T. Kitamura et al., Retrovirus-mediated gene transfer and expression cloning: powerful tools in functional genomics. Exp. Hematol. 31, 1007-1014 (2003). doi:10.1016/j.exphem.2003.07.005

31. R. Higuchi, in PCR protocols: A guide to methods and applications. (Academic Press, San Diego, 1990), pp. 177-188.

32. F. Kontgen et al., Targeted disruption of the MHC class II Aa gene in C57BL/6 mice. Int. Immunol. 5, 957-964 (1993). doi:10.1093/intimm/5.8.957

33. K. Sakai, J. i. Miyazaki, A transgenic mouse line that retains Cre recombinase activity in mature oocytes irrespective of the cre transgene transmission. Biochem. Biophys. Res. Commun. 237, 318-324 (1997). doi:10.1006/bbrc.1997.7111 
34. H. Kanki, H. Suzuki, S. Itohara, High-efficiency CAG-FLPe deleter mice in C57BL/6J background. Exp. Anim. 55, 137-141 (2006).

35. J. A. Cattermole et al., Isolation of murine fetal thymus cell lines after infection with recombinant retroviruses containing the v-myc and v-Ha-ras oncogenes. J. Immunol. 142, 3746-3753 (1989).

36. T. Imao, S. Nagata, Apaf-1- and Caspase-8-independent apoptosis. Cell Death Differ 20, 343-352 (2013). doi:10.1038/cdd.2012.149

37. T. Akagi, K. Sasai, H. Hanafusa, Refractory nature of normal human diploid fibroblasts with respect to oncogene-mediated transformation. Proc. Natl. Acad. Sci. USA 100, 13567-13572 (2003). doi:10.1073/pnas.1834876100

38. J. D. Watson et al., Effect of IL-7 on the growth of fetal thymocytes in culture. $J$. Immunol. 143, 1215-1222 (1989).

39. R. Watanabe-Fukunaga et al., The cDNA structure, expression, and chromosomal assignment of the mouse Fas antigen. J. Immunol. 148, 1274-1279 (1992).

40. J. Ogasawara et al., Lethal effect of the anti-Fas antibody in mice. Nature 364, 806809 (1993). doi:10.1038/364806a0

41. M. Tanaka, T. Suda, T. Takahashi, S. Nagata, Expression of the functional soluble form of human Fas ligand in activated lymphocytes. EMBO J. 14, 1129-1135 (1995).

42. Y. Aoki et al., A novel peptide probe for studying the transbilayer movement of phosphatidylethanolamine. J. Biochem. 116, 291-297 (1994).

43. S. Toda, R. Hanayama, S. Nagata, Two-step engulfment of apoptotic cells. Mol. Cell Biol. 32, 118-125 (2012). doi:10.1128/MCB.05993-11

44. S. Brenner, The genetics of Caenorhabditis elegans. Genetics 77, 71-94 (1974).

Acknowledgments: We thank W. Hiraoka, M. Umeda and M. Fujii for PLB-985 cell line, RO09-0198 peptide, and secretarial assistance. Supported in part by Grants-in-Aid for Specially Promoted Research from the Japan Society for the Promotion of Science (JSPS) to S.N., and Grant-in-Aid for Young Scientists (B) from JSPS to J.S., and by postdoctoral fellowships from the Damon Runyon Cancer Research Foundation and from the Charles A. King Trust to D.P.D. H.R.H. is the David H. Koch Professor of Biology at the Massachusetts Institute of Technology and an Investigator at the Howard Hughes Medical Institute. 
Fig. 1. Xkr8-mediated PtdSer exposure. (A) Staining of Ba/F3 and LD-PS5-2-2 cells with Cy5-Annexin V. (B) WR-Fas cells and transformants expressing mXkr8-GFP or mTMEM16F-GFP were treated with FasL and stained with Cy5-Annexin V. (C) WR-Fas cells transformed with scrambled shRNA, mXkr8 shRNA, or both $\mathrm{mXkr} 8$ shRNA and $\mathrm{h} X k r 8$ cDNA were treated with FasL and stained with Cy5-Annexin V. Representative FACS profiles for each group are shown. (D) 293T cells expressing hXkr8-GFP were observed by fluorescence microscopy. Scale bar, $10 \mu \mathrm{m}$.

Fig. 2. Epigenetic repression of Xkr8 in human cancer cell lines. (A) Abundance of $\mathrm{h} X k \mathrm{r} 8$ mRNA relative to $\beta$-actin mRNA was determined by real-time RT-PCR. (B) The indicated cell lines and hXkr8 transformants were treated with apoptotic stimuli, and stained with Cy5Annexin V. (C) PLB-985 cells and hXkr8-transformants were treated with UV, labeled with pHrodo, and incubated with peritoneal macrophages. FACS profiles for pHrodo-positive cells

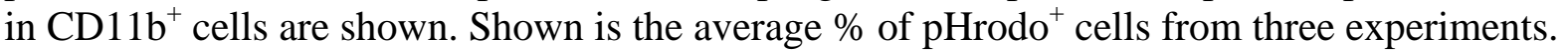
Right, macrophages (arrows) engulfing apoptotic cell were observed by fluorescence microscopy. (D) PLB-985 cells were treated with DAC, and $X k r 8$ mRNA was quantified relative to GADPH mRNA by real-time RT-PCR. (E) PLB-985 cells were treated with DAC for 5 days, exposed to UV, and stained with Cy5-Annexin V and PI.

Fig. 3. Activation of Xkr8 by caspase cleavage. (A and B) PLB-985 and transformants expressing hXkr8-GFP or hXkr8 2DA-GFP were treated with staurosporine (STS) and stained with Cy5-Annexin V (A). In (B), the cell lysates were analyzed by western blotting with anti-GFP and anti-ICAD antibodies. (C) WR-Fas and transformants expressing GFP, mXkr8-GFP or mXkr8 2DA-GFP were treated with FasL. Cell lysates were analyzed by western blotting with anti-GFP. (D) The membrane fraction of PLB-985 cells expressing $\mathrm{hXkr8-GFP}(\mathrm{W})$ or the 2DA mutant was incubated with human caspases (C1 to C10, caspase1 to caspase-10) and analyzed by western blotting with anti-GFP antibody.

Fig. 4. Promotion of PtdSer exposure and cell-corpse engulfment by mouse Xkr8 and $C$. elegans CED-8. (A) MEFs from $\mathrm{Xkr}^{+/}$and $\mathrm{Xkr8^{-/ }}$ embryos were treated with staurosporine (STS) or control buffer for $8 \mathrm{~h}$ and stained with Cy5-Annexin V. (B) IFETs of the indicated genotypes were treated with FasL and stained with Cy5-Annexin V and PI. (C) The number of floater cells per egg was counted for each genotype. Error bars, standard deviation; ***, p $<0.0001$ in a Student's t-test for each pair-wise comparison between ced-x and ced-8; ced-x double mutants. (D) PtdSer was detected using MFG-e8::Venus. Shown is the cell corpse of P12.aap (arrowhead), which undergoes apoptosis and is engulfed by P12.pa (arrow). The death of P12.aap is accompanied by PtdSer exposure in wild-type but not in ced-8 (n1891) animals. In addition, P12.pa, like other $C$. elegans engulfing cells $(23,24)$, exposes PtdSer on its outer plasma membrane during engulfment. 
A

Ba/F3 LD-PS0

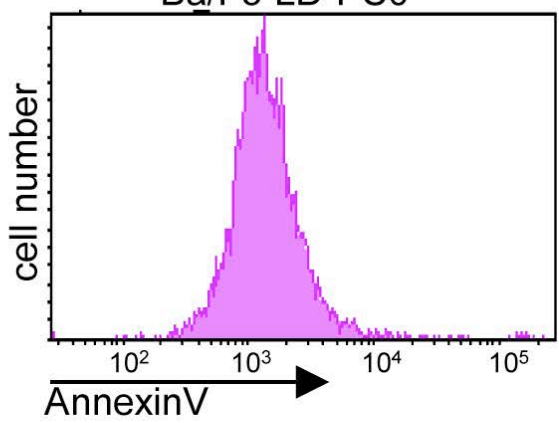

Ba/F3 LD-PS5-2-2

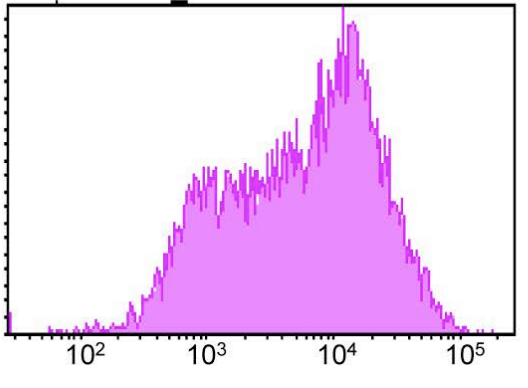

mXkr8-GFP

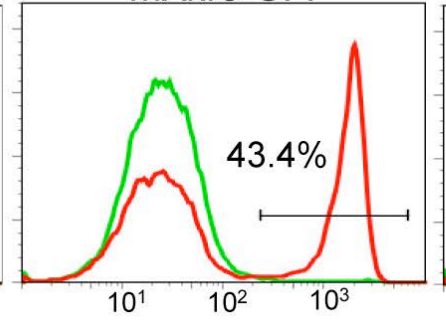

shXkr8

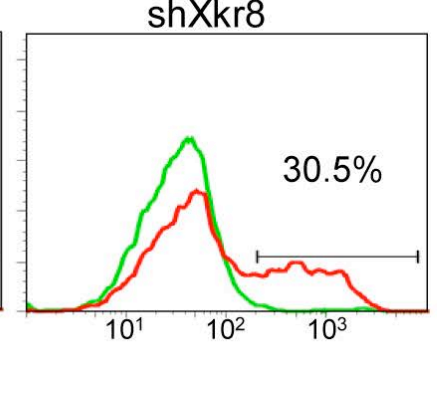

mTMEM16F-GFP

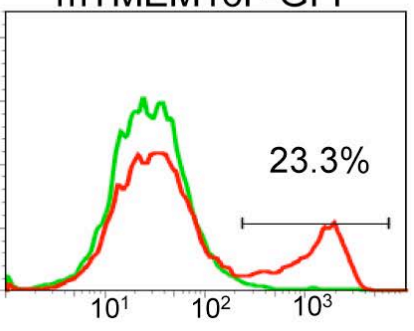

shXkr8 +hXkr8

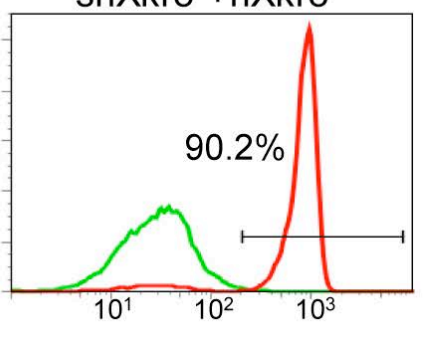

D

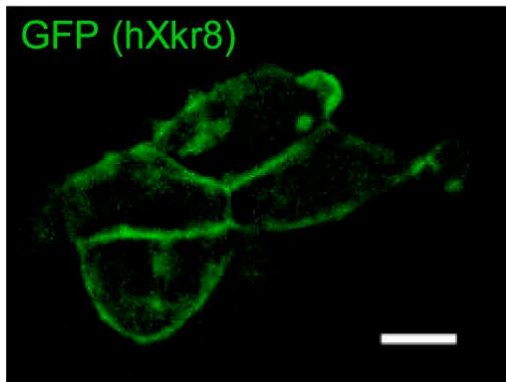

Phase

Suzuki et al. Figure 1 

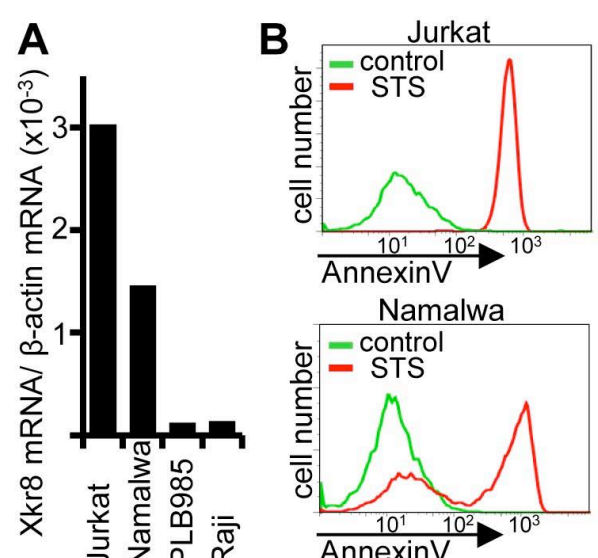

PLB985
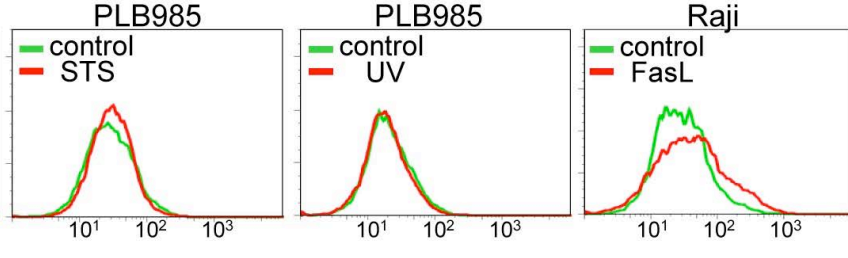

Namalwa

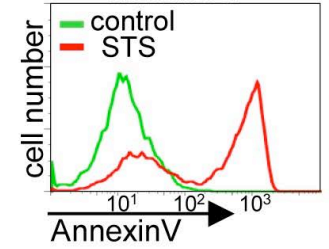

PLB985 +hXkr8

PLB985 +hXkr8 Raji + hXkr8
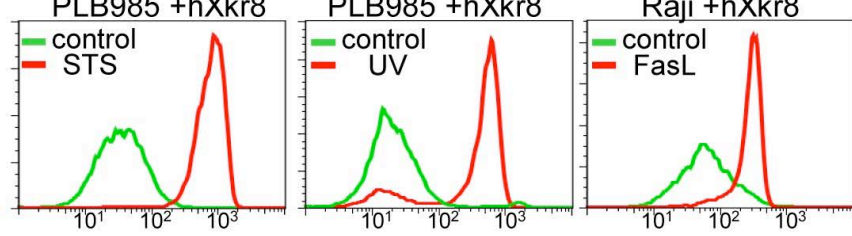

C macrophages

macrophages macrophages apoptotic PLB apoptotic PLB+hXkr8

macrophages apoptotic PLB+hXkr8
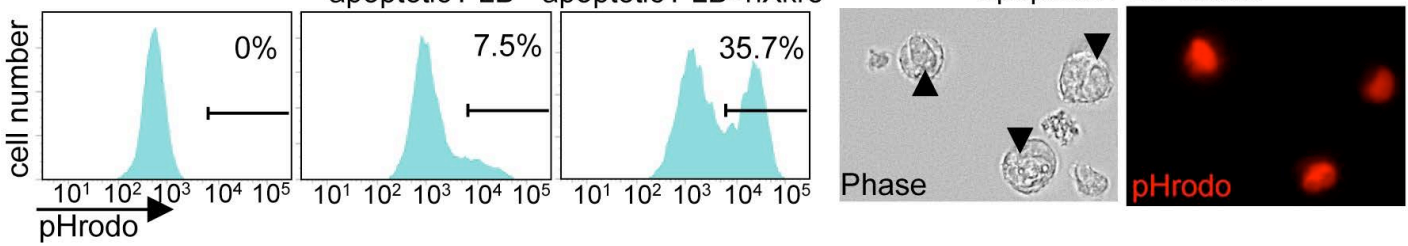

D

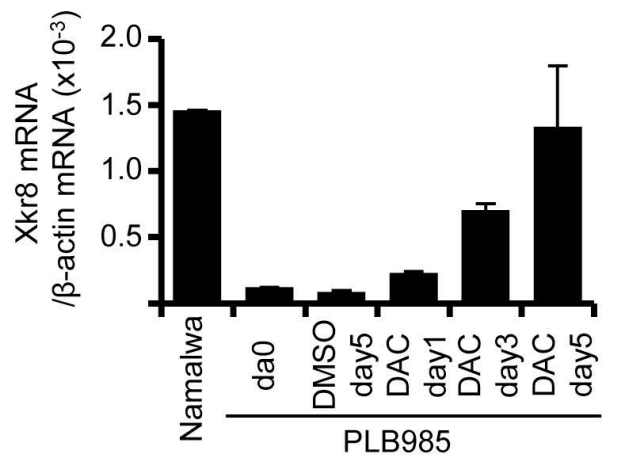

E

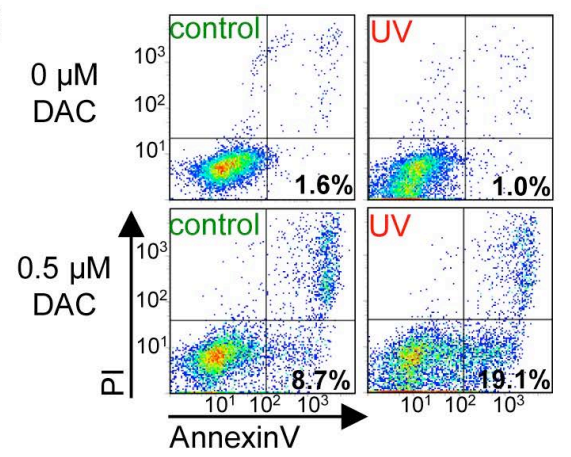

Suzuki et al. Figure 2 
A

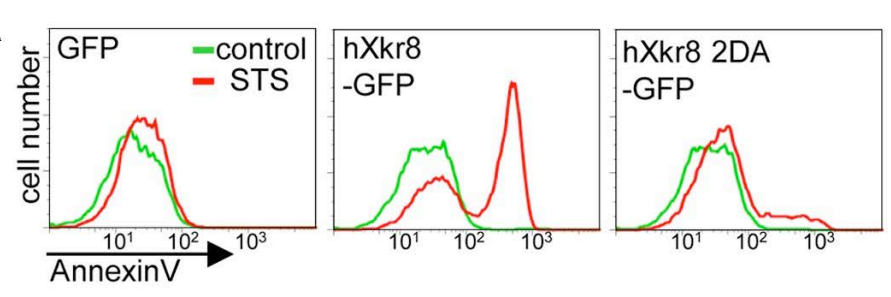

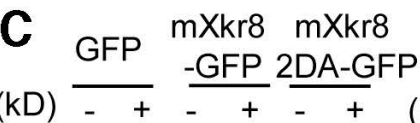

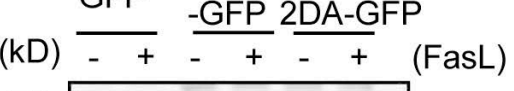

AnnexinV
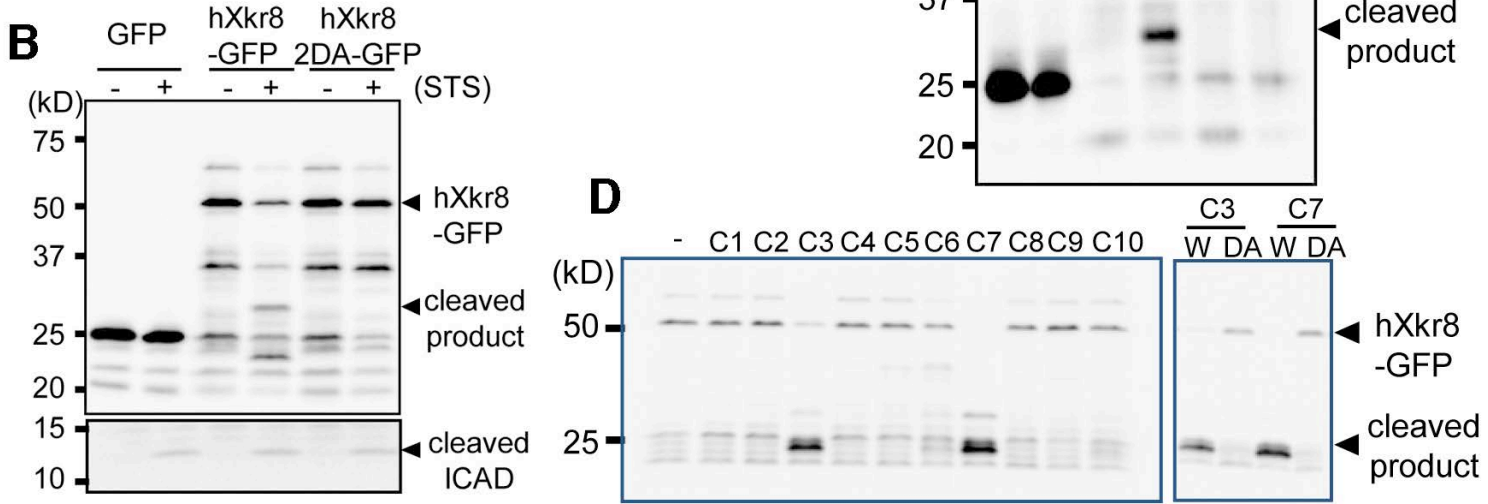

Suzuki et al. Figure 3 
A

B
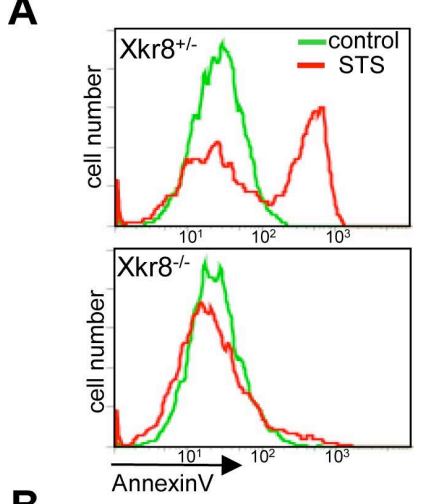

Xkr8till

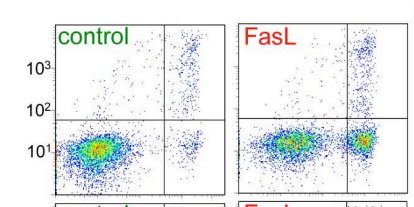

$\mathrm{Xkr8}^{-1}$

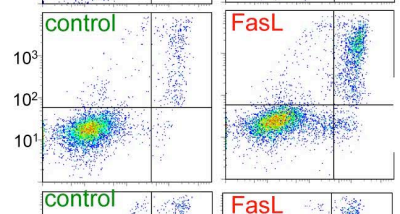

$\mathrm{Xkr8}^{-1-}$
$+\mathrm{mXkr8}$
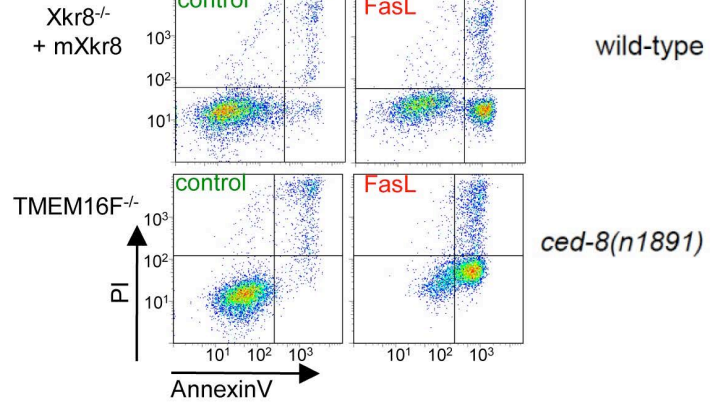

D

wild-type
C
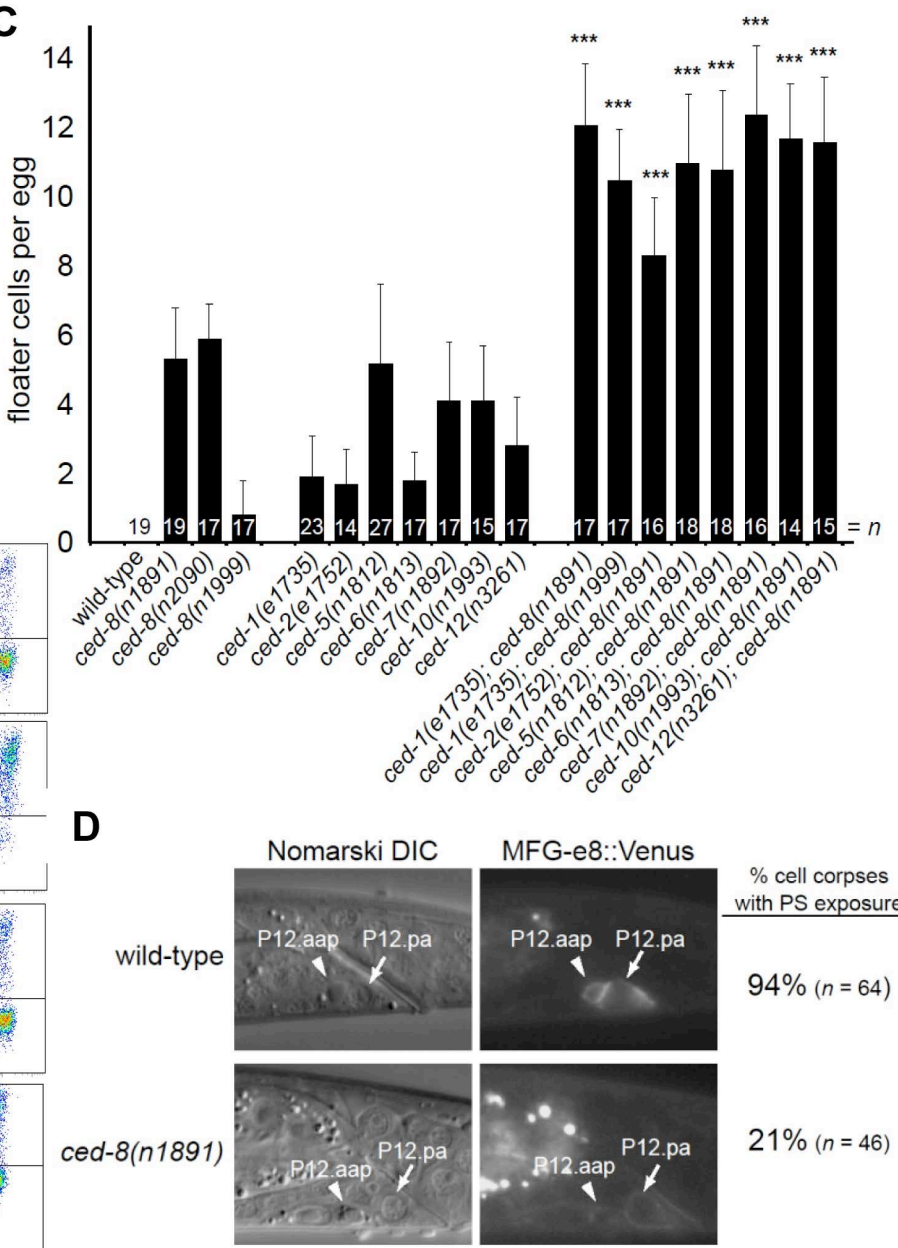

$21 \%(n=46)$

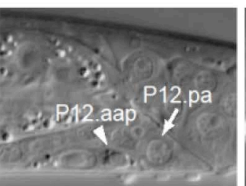

$\%$ cell corpses with PS exposure

$94 \%(n=64)$

(n)

Suzuki et al. Figure 4 


\section{Supplementary Materials for}

Xk-related protein 8 and CED-8 promote the exposure of phosphatidylserine on the surfaces of apoptotic cells

Jun Suzuki, Daniel P. Denning, Eiichi Imanishi, H. Robert Horvitz, and Shigekazu Nagata.

correspondence to: snagata@mfour.med.kyoto-u.ac.jp

This PDF file includes:

Materials and Methods

Figs. S1 to S15 


\section{Materials and Methods}

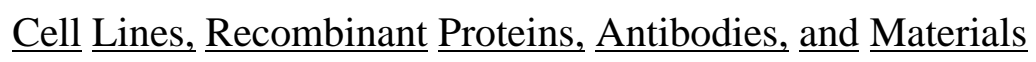

Mouse interleukin-3 (IL-3)-dependent Ba/F3 cells (25) were maintained in RPMI-10\% fetal calf serum (FCS, Gibco), 45 units/ml mouse IL-3, and $50 \mu \mathrm{M} \beta$-mercaptoethanol. Human PLB-985 (26), Jurkat, Namalwa, and Raji cells were grown in RPMI1640-10\% FCS and $50 \mu \mathrm{M} \beta$ mercaptoethanol. Plat-E packaging cells (27) were grown in DMEM-10\% FCS. Mouse IL-3 (28), and human FasL (29) were prepared as described. Rabbit anti-activated caspase-3 mAb was from Cell Signaling. Mouse anti-human ICAD mAb was from Medical \& Biological Laboratories, and Alexa 488-labeled goat anti-rabbit IgG Abs were from Invitrogen. Staurosporine was provided by Kyowa Hakko Kirin.

Construction of the cDNA Library, and Identification of Xkr8

Using poly(A) RNA from Ba/F3-PS19 cells, cDNA was synthesized with random hexamers as primers, and a BstXI adaptor was attached as described (5). DNA fragments 1.0 to $2.5 \mathrm{~kb}$ in length were size-fractionated by electrophoresis through a $1 \%$ agarose gel and ligated into a BstXIdigested pMXs vector (30). Approximately $1.3 \times 10^{6}$ clones were produced with $E$. coli DH10B cells (ElectroMax DH10B; Invitrogen) by electroporation. Using plasmid DNA from the cDNA library, retrovirus was produced in Plat-E cells, concentrated by centrifugation, and used to infect $\mathrm{Ba} / \mathrm{F} 3$ cells as described (5). Cells treated with A23187 were stained on ice for 15 min with Cy5Annexin V (Biovision) and for 2 min with $5 \mu \mathrm{g} / \mathrm{ml}$ Propidium Iodide, and sorted with a FACSAria (BD Biosciences). The cDNA integrated into the retroviral vector was identified by PCR (5) as the Xkr8 cDNA. Real-time PCR indicated that the amount of Xkr8 mRNA in Ba/F3-PS19 is similar to that in the parental $\mathrm{Ba} / \mathrm{F} 3$ cells, suggesting that the strong PtdSer exposure in $\mathrm{Ba} / \mathrm{F} 3-\mathrm{PS} 19$ cells is due to the mutation introduced into TMEM16F gene (5).

Expression Plasmids for Mouse and Human Xkr8, and Their Mutants

The coding sequences for $\mathrm{mXk} r 8$ (GenBank NM_201368) and hXkr8 (GenBank NM_018053) were prepared by RT-PCR from Ba/F3 and Namalwa cells, respectively. The pMXs puro c-GFP was constructed by inserting the GFP sequence into pMXs puro. The $X k r 8$ cDNAs were then inserted into pMXs puro c-FLAG (5) or pMXs puro c-GFP to express proteins tagged with FLAG or GFP at the C-terminus. To generate the D351A/D354A (2DA) mutant of $\mathrm{mXkr8}$, and the D352A/D355A (2DA) mutant of $\mathrm{h} X k r 8$, the mouse and human $X k r 8 \mathrm{cDNAs}$ were mutated by recombinant PCR (31) using primers carrying the mutated nucleotides.

Primers used to prepare the $\mathrm{m} X k r 8$ and $\mathrm{h} X k r 8 \mathrm{cDNA}$ were as follows (in each primer, the $B a m \mathrm{HI}$ or EcoRI recognition sequence is underlined): $\mathrm{mXkr8,5}$ 'ATATGGATCCATCATGCCTCTGTCCGTGCACCA-3' and 5'ATATGAATTCGAGGACTCCATTCAGCTGCA-3'; hXkr8, 5' ATATGGATCCGCCATGCCCTGGTCGTCCCGCGG-3' and 5'ATATGAATTCTCCCTTCACTGGCGAAGCAG-3'. Primers used to generate the D351A/D354A (2DA) mutants of $\mathrm{mXkr} 8$, and the D352A/D355A (2DA) mutants of $\mathrm{h} X k r 8$ were : $\mathrm{mXkr8} 2 \mathrm{DA}, 5^{\prime}$ GGGACCCTGCCCTCGTGGCTGGGACCCTAG-3', and 5' CTAGGGTCCCAGCCACGAGGGCAGGGTCCC-3' and hXkr8 2DA, 5'AAGCCCGACCCTGCCCAGGTAGCCGGGGCC-3' and 5' GGCCCCGGCTACCTGGGCAGGGTCGGGCTT-3'. 


\section{ShRNA}

Four shRNA expression plasmids for $\mathrm{m} X k r 8$ and scrambled shRNA in a pRS vector were purchased from OriGene. Among the four $\mathrm{mXkr} 8$ target sequences, the most effective was 5'GAATCTGTGCCATCGCCTTGTTCTCAGCT-3'. WR19L cells were transfected by electroporation, and stable transformants were selected in medium with $1.0 \mu \mathrm{g} / \mathrm{ml}$ puromycin, and subjected to cloning by limited dilution. The $X k r 8$ mRNA was quantified by real-time RT-PCR.

\section{Establishment of $\underline{X r 8}$ Knock-out Mice}

$X k r 8$ conditionally targeted mice were generated by Unitech as a custom order. In brief, a neo-loxP cassette carrying the phosphoglycerate kinase promoter-driven neomycin-resistance gene flanked by FRT sequences was inserted into intron 3 of the $X k r 8$ gene. A 1.0-kb fragment containing exon 3 was replaced with a fragment carrying the corresponding sequence and a loxP sequence. The diphtheria toxin A-fragment driven by the thymidine kinase promoter was inserted at the 5' end of the vector. Mouse Bruce-4 embryonic stem cells (32) were transfected with the targeting vector, and the G418-resistant clones were screened for homologous recombination by PCR. Positive clones were used to generate $X k r 8^{+/ N e o F R T}$ mice, which were crossed with transgenic mice carrying cytomegalovirus enhancer-chicken b-actin hybrid promoter (CAG)-driven Cre recombinase gene $(C A G-C R E)(33)$ or CAG-driven flippase variant $(F L P e)$ gene $(C A G-F L P e)(34)$. The resulting mice were backcrossed to the wild-type C57BL/6 to generate $X k r 8^{+/-}$or $X k r 8^{+/ f l o x}$ mice. Intercrosses of $\mathrm{Xkr}^{+/-}$mice generated $\mathrm{Xkr8^{-/ }}$ mice in a normal Mendelian ratio. All the mice were housed in a specific pathogen-free facility at Kyoto University, and all the animal experiments were carried out in accordance with protocols approved by Kyoto University.

Mouse Embryonic Fibroblasts and Fetal Thymocyte Cell Lines

Fibroblasts were prepared form E14.5 embryos of $\mathrm{Xkr}^{+/-}$and $\mathrm{Xkr}^{-/-}$mice, and cultured in DMEM containing $10 \%$ FCS. A fetal thymocyte cell line (IFET) was established by immortalizing fetal thymocytes with $\mathrm{H}$-ras ${ }^{V 12}$ and $c$-myc as described $(35,36)$. In brief, $\mathrm{Xkr}^{+ \text {fllox }}$ mice were intercrossed, and thymocytes were obtained on embryonic day 14.5. Retrovirus carrying the genes for $H$-ras ${ }^{V 12}$ and $c-m y c$ was produced in Plat-E cells with the pCX4 vector (37), and bound to RetroNectin-coated plates (Takara Bio) by centrifugation at 2,000 x $g$ for 2-3 h. The thymocytes were attached to the retrovirus-coated plate by centrifugation at $400 \mathrm{x} g$ for $5 \mathrm{~min}$, and cultured in DMEM-10\% FCS, 1 x non-essential amino acids, $10 \mathrm{mM}$ Hepes- NaOH buffer (pH 7.4), $50 \mu \mathrm{M} \beta$ mercaptoethanol, $5 \mathrm{ng} / \mathrm{ml}$ mouse IL-7 (38) (PeproTech), and GlutaMax ${ }^{\mathrm{TM}}$ (Gibco). The resultant IFET cells were infected with Adeno-Cre (Adenovirus Cre/loxP, Takara Bio), and subjected to cloning by limited dilution. The $T M E M 16 F^{-/}$IFET cell line was described previously (6).

Transformation of Human and Mouse Cells

Retroviruses carrying a $X k r 8$ cDNA were produced by introducing the pMX-puro vector into Plat-E cells, concentrated by centrifugation, and used to infect $X k r 8^{-/-}$IFET cells. Stable transformants were selected in medium containing $2.0 \mu \mathrm{g} / \mathrm{ml}$ puromycin, and the expression of recombinant protein was confirmed by Western blotting with an anti-Flag Ab (Clone M2, Sigma) or anti-GFP Ab (Clone JL8, Clontech). Mouse Fas cDNA (39) was introduced into IFET cells by retrovirus- mediated transformation, and its expression was confirmed by flow cytometry with the anti-mouse Fas mAb (Jo2) (40). Human PLB-985 and mouse WR19L cells were transformed by retrovirus infection with amphotropic retrovirus envelope or VSV $\gamma$ envelope. In brief, retrovirus was generated by transfecting 293 T cells with the pMXs retrovirus vector, pGP (Takara Bio) for 
Gag and pol-fusion protein, and pE-ampho (Takara Bio) or pCMV-VSV-G-RSV-Rev (provided by Dr. H. Miyoshi, Riken). Virus in the culture supernatant was concentrated by centrifugation and used to transform cell lines. To express Xkr8-GFP, 293T cells were transfected with pMXs puroXkr8-GFP with Fugene 6 (Promega), and transformants were selected in medium containing $1.0 \mu \mathrm{g} / \mathrm{ml}$ puromycin.

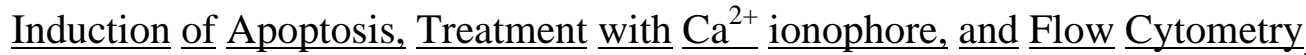

Apoptosis was induced with FasL, staurosporine, or UV. In brief, 5 x $10^{5}$ cells in $500 \mu$ l of medium were incubated at $37^{\circ} \mathrm{C}$ with $10-400 \mathrm{units} / \mathrm{ml} \mathrm{hFasL}$ for $1.2-2.0 \mathrm{~h}$ or with $10 \mu \mathrm{M}$ staurosporine for 1.5-8.0 h. For UV exposure, $1 \times 10^{6}$ cells in $2 \mathrm{ml}$ of PBS were exposed to 500$2000 \mathrm{~J} / \mathrm{m}^{2} \mathrm{UV}$ radiation $\left(254 \mathrm{~nm}\right.$ ) in a StrataLinker (Stratagene), and incubated at $37^{\circ} \mathrm{C}$ for $1.5-2.0$ $\mathrm{h}$ in $4 \mathrm{ml}$ of RPMI1640-10\% FCS. The cell viability was assayed by WST-1 assay with 2-(4Iodophenyl)-3- (4-nitrophenyl)-5-(2,4-disulfophenyl)-2H-tetrazolium, monosodium salt (WST-1; Dojin Laboratories) and 1-Methoxy-5-methylphenazinium methylsulfate as described (41). To detect the apoptotic DNA fragmentation, DNA extracted from cells was analyzed by electrophoresis on $1.5 \%$ agarose gel. To detect active caspase- $3,1 \times 10^{6}$ cells were fixed at $37^{\circ}$ for 10 min in PBS containing $1 \%$ paraformaldehyde, washed with chilled PBS- $0.5 \%$ BSA, and permeabilized by overnight incubation at $-20^{\circ} \mathrm{C}$ in $90 \%$ methanol. Cells in $100 \mu \mathrm{l}$ of PBS- $0.5 \%$ BSA were then incubated with 200-fold-diluted rabbit anti-active caspase-3 at room temperature for $30 \mathrm{~min}$, followed by incubation for $30 \mathrm{~min}$ with 1,000- fold-diluted Alexa 488-labeled goat antirabbit IgG. The cells were washed with PBS-0.5\% BSA, filtered into the FACS tube, and analyzed by a FACSAria. To monitor A23187-induced PtdSer exposure, 5 x $10^{5}$ cells in $500 \mu$ l of Annexin V staining buffer (10 mM Hepes-NaOH buffer [pH7.4] containing $140 \mathrm{mM} \mathrm{NaCl}$ and $2.5 \mathrm{mM} \mathrm{CaCl}_{2}$ ) were treated with 3.0-10 $\mu \mathrm{M}$ A23187, and analyzed with a FACSAria at $20^{\circ} \mathrm{C}$.

Assay for Phospholipid Scrambling Activity

To detect phosphatidylserine (PtdSer) and phosphatidylethanolamine (PtdEtn) on the cell surface, cells were stained on ice for 15 min with 2500-5000-fold diluted Cy5-Annexin V (Biovision) or 800-fold diluted biotin-Ro09-0198 (42) followed by $1.0 \mu \mathrm{g} / \mathrm{ml}$ APC- streptavidin in Annexin V staining buffer in the presence of $5 \mu \mathrm{g} / \mathrm{ml}$ propidium iodide, and analyzed by a FACSAria or FACSCalibur (BD Biosciences). To assay the internalization of phosphatidylcholine (PtdCho) and sphingomyelin (SM), 1 x $10^{6}$ cells in $0.5 \mathrm{ml}$ of Hank's Balanced Salt Solution (HBSS) containing $1 \mathrm{mM} \mathrm{CaCl}$ (HBSS-Ca) were incubated on ice for $7 \mathrm{~min}$. An equal volume of 200 nM 1-oleoyl-2-\{6-[(7-nitro-2-1,3- benzoxadiazol-4-yl)amino]hexanoyl \}-sn-glycero-3phosphocholine (NBD-PC)(Avanti Polar Lipids), or N-[6-[(7-nitro-2-1,3-benzoxadiazol-4yl)amino]hexanoyl]-sphingosine-1- phosphocholine (NBD-SM) (Avanti Polar Lipids) in HBSS-Ca was added, and incubated at $20^{\circ} \mathrm{C}$. Aliquots $(150 \mu \mathrm{l})$ were mixed with $150 \mu \mathrm{l}$ HBSS containing 5 $\mu \mathrm{g} / \mathrm{ml}$ fatty-acid free BSA (Sigma-Aldrich) and $500 \mathrm{nM}$ Sytoxblue (Molecular Probes), and analyzed by FACSAria.

\section{Engulfment of Apoptotic Cells by Macrophages}

Engulfment of apoptotic cells by macrophages was assayed essentially as described previously (43). In brief, cells were treated with UV to induce apoptosis and labeled with $0.1 \mu \mathrm{g} / \mathrm{ml}$ pHrodo succinimidyl ester (pHrodo, Invitrogen). Thioglycollate-elicited peritoneal macrophages were prepared from mouse peritoneal cavity 4 days after injection of $2 \mathrm{ml}$ of $3 \%$ thioglycollate, and 
incubated with apoptotic cells at $37^{\circ} \mathrm{C}$ for $2 \mathrm{~h}$. The pHrodo-positive population in $\mathrm{CD}_{11 \mathrm{~b}^{+}}$ macrophages was regarded as the cells engulfing apoptotic cells.

Treatment with 5-aza-2'-deoxycytidine, and Bisulfite Genomic Sequencing

To treat human PLB-985 cells with 5-aza-2'-deoxycytidine (DAC, Sigma-Aldrich), $1.0 \times 10^{6}$ cells in $10 \mathrm{ml}$ of RPMI-10\% FCS were incubated with $0.5 \mu \mathrm{M}$ DAC for up to 7 days. Since DAC is an unstable compound, the medium was changed every $24 \mathrm{~h}$. After DAC treatment, the cells were divided into three portions: one for FACS to analyze the PtdSer exposure, one for real-time RTPCR for Xkr8 expression, and one for methylation-specific PCR analysis (12). For the bisulfite genomic sequencing, DNA was modified with bisulfite using a kit (MethyEasy Xceed, Human Genetic Signatures). In brief, $3 \mu \mathrm{g}$ DNA was denatured at $37^{\circ} \mathrm{C}$ for $15 \mathrm{~min}$ in $0.3 \mathrm{M} \mathrm{NaOH}$, and treated with sodium bisulfite according to the protocol provided by the supplier except that the incubation time was changed to $90 \mathrm{~min}$. The modified DNA was denatured at $95^{\circ} \mathrm{C}$ for $20 \mathrm{~min}$, and amplified by PCR using primers (TTAGGGATTAGAATGTGTTT and CCTATACAAATAACCCAACT). PCR was carried out with EpiTaq HS polymerase (Takara Bio), and the product was cloned into the pGEM-Teasy vector for sequencing.

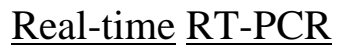

Total RNA was reverse-transcribed using Superscript III reverse-transcriptase (Invitrogen) or High Capacity RNA-to-cDNA ${ }^{\mathrm{TM}}$ kit (Applied Biosystems). Specific cDNA was amplified in a reaction mixture containing LightCycler®480 SYBR Green I Master (Roche Diagnostics), and the mRNA was quantified at the point where the LightCycler System detected the upstroke of the exponential phase of PCR accumulation with the linearized plasmid DNA as reference. Primers for real-time RT-PCR were: $\mathrm{mXkr8,} \mathrm{5'-GCGACGCCACAGCTCACACT-3'} \mathrm{and} \mathrm{5'-}$ CCCCAGCAGCAGCAGGTTCC-3'; mGapdh, 5'-AGCAGGCATCTGAGGGCCCA-3' and 5'GAGAGCAATGCCAGCCCCGG-3'; hXkr8, 5'-AGGCCGGGCCATCATCCACT-3' and 5'TGCGCCTGTTCTGAGGCAGC-3'; and h $\beta$-actin, 5'-GCATCCTCACCCTGAAGTAC-3' and 5'CTTAATGTCACGCACGATTTC-3'.

\section{Caspase Treatment of Cell Lysates}

The membrane fraction was prepared from PLB-985 transformants expressing hXkr8-GFP or hXkr8 2DA-GFP as described (28) and solubilized in $20 \mathrm{mM}$ Tris-HCl buffer (pH 7.2)-140 mM $\mathrm{NaCl}, 1 \%$ Triton X-100, 10\% glycerol, and $1 \mathrm{mM}$ ( $p$-aminophenyl) methanesulfonyl fluoride (APMSF). After removing insoluble materials by centrifugation, the membrane proteins $(20 \mu \mathrm{g})$ were incubated at $37^{\circ} \mathrm{C}$ for $1 \mathrm{~h}$ with 3 units of various recombinant human caspases (Biovision) in $100 \mu \mathrm{l}$ of $50 \mathrm{mM}$ Hepes- $\mathrm{NaOH}$ (pH 7.4), $50 \mathrm{mM} \mathrm{NaCl}, 5 \%$ glycerol, $5 \mathrm{mM}$ DTT, $10 \mathrm{mM}$ EDTA, $0.1 \mathrm{mM}$ APMSF and $0.1 \%$ CHAPS, and analyzed by Western blotting.

\section{Western Blotting}

Cells were lysed in RIPA buffer (50 mM Hepes-NaOH buffer [pH 8.0], 1\% NP-40, 0.1\% SDS, $0.5 \%$ sodium deoxycholate, $150 \mathrm{mM} \mathrm{NaCl}$, and $10 \%$ protease inhibitor cocktail). The lysates were mixed with 5 x SDS sample buffer (200 mM Tris-HCl [pH 6.8], 10\% SDS, 25\% glycerol, 5\% $\beta$ mercaptoethanol, and $0.05 \%$ bromophenolblue), and incubated at room temperature for $1 \mathrm{~h}$ to detect Xkr8-GFP, or boiled for 5 min to detect other proteins. Proteins were separated by SDSPAGE on a $10-20 \%$ gradient gel (Bio Craft), and transferred to a PVDF membrane (Millipore). The membranes were probed with 3000-fold-diluted mouse anti-GFP mAb, 3000-fold-diluted mouse 
anti-human ICAD mAb, or 3000-fold-diluted rabbit anti-active caspase- $3 \mathrm{mAb}$ followed by incubation with 1,000-fold-diluted HRP-conjugated goat anti-mouse or rabbit Igs (Dako). The peroxidase activity was detected by the Western Lightning ${ }^{\circledR}$-ECL system (PerkinElmer).

\section{C. $\underline{\text { elegans }} \underline{\text { Strains, }}$ Plasmids and Experimental Procedures}

C. elegans strains were cultured as described (44) and maintained at $20^{\circ} \mathrm{C}$. The Bristol strain N2 was used as the wild-type strain. Mutations used are listed below:

LGI: $c e d-1(e 1735, n 2091)$.

LGIII: ced-6(n1813), ced-7(n1892), ced-12(n3261).

LGIV: ced-2(e1752), ced-3(n3692, n2424), ced-5(n1812), ced-10(n1993).

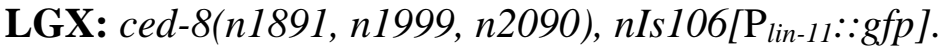

unknown linkage: $n I s 398\left[\mathrm{P}_{d y n-1}:: m f g-e 8::\right.$ Venus, $\left.\mathrm{P}_{m y o-2}:: d s R e d\right]$.

Shed cells or floaters were counted in eggs between the 2-fold and 3.5-fold stages of development (approximately 450-600 min after the first cell division) using a Zeiss Axioskop wide-field microscope equipped with a 100x objective equipped and Nomarski differential interference contrast (DIC) optics as described (17). PtdSer exposure on the corpses was detected using secreted MFG-e8::Venus expressed from the transgene nIs398 (18). All images were acquired using OpenLab software (PerkinElmer) and modified for publication using ImageJ. 
Mouse rat human

Fugu

medaka

mouse

rat

human

Fugu

medaka

Xenopus

mouse

rat

human

Fugu

Medaka

Xenopus

mouse

rat

human

Fugu

Medaka

Xenopus

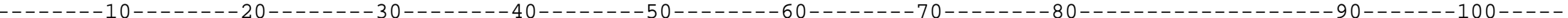
MP LSVHHHVALDVVVGLVS ILSF LLDLVADLWAVVQYVLLGRYLWAALVLVLLGQASVLLQLF SWLWLTADP TELHHSQLSRPF-----------LALLHLLQLGYLYRCLHGMHQ MP LSVHPQVALDVVI GLVSTLSF LLDLVADLWAVVQYVLVGRYLWAALVVVLLGQASVLLQLF SWLWLTADP TELHQLQP SRRF------------LALLHLLQLGYLYRCLHGMRQ MPWSSRGALLRDLVLGVLGTAAF LLDLGTDLWAAVQYALGGRYLWAALVLALLGLASVALQLF SWLWLRADPAGLHGSQPPRRC-----------LALLHLLQLGYLYRCVQELRQ MRVMGQATISNYSWIDFVF SVIGVFTFFVDWGADVWVATEFYSRGDFFWFGLLVSLMVLSSVLVQMF SWFWLKYDRELPDVCRQSGGGTVLFGDRVQL-SWLLHVLQLGF LCRH I SA IRQ

MAVFTFSP LDFVF SCLGLP LF LADVVLDVLAVIDFYKEEAWVRLSVLLLLLVGSSVLIOVYSWKWYIGDGLDLKTRVESALKKG---------LKTLHVLQLGIYVRHLGVLEK MPACCPPRYRLLDLVFALGGTLTF LLDLGSDVWGALAYYRAGDVAWAALLIGFYGMASLVLQLHSWGWFWTDRRSGNIWELPRDPP HRAGSGSASTYTERGP GELNARESASCGC I H

$--110-------------120------130-------140-------150-------160-------170-------180-------190-------200-------210--------$ GLSMCYQEMP S------ECDLAYADF LSLD I SMLKLFESF LEATPQLTLVLAIVLQNGQAEYYQWFGISS SF LGISWALLDYHRS LRTCLP SKPRLGRS S SAIYFLWNLLLLGPRICA I GLSMCCQEVP S------ECDLAYADF LSLD I SMLRLFESFLEATPQLTLVLAIVLQSGNAEYYQWFGISS SF LGISWALLDYHRS LRTCLP SKPRLGWCS SAVYFLWNLLLLGPRICA I GLLVWQQEEP S-------EFDLAYADF LALD I SMLRLFETF LETAP QLTLVLAIMLQSGRAEYYQWVGICTSF LGI SWALLDYHRALRTCLP SKP LLGLGS SVIYF LWNLLLLWP RVLAV GFRVWWRQQEG----------SEYAVYLTHDLSMLRL IE TF SESAP QLTLMVHVMLCTNRARTVQ-----------SWMVVDYHRS LRAF LP DKAKQGWGS S LIYF LWNF LL IAPRVAAL SVSGFCGKGSDS------QNSKDVAVELSHDLCMLHLIETF SESAP Q IVLWLT I I LQDGK---------------------------LDD SNQLS I ISS I I HF LWNLLLLLSRLTAL SLEVGIAAYRSSENNP TYDRYQEYAYFLTHD I SMMRLMETF LENTPQLILLLY IVLHRGT IYTFQYF S IS ISF IS ISWA ILDYHQSLRLF LKDKQSMNI LS S I IYF LWNLLL IF SRIVC I

$220-------230-------240-------250-------260-------270-------280-------290-------300-------310-----------320-------330----$ ALF SAVFPYYVALHFF SLWLVLLFWIWLQGTNFMPD SKGEWLYRVTMALILYF SWFNVSGGRTRGRAVIHLIF IF SDSVLLVTTSWVTHGTWLP----SGISLLMWVT IGGACFFLGLAL ATF SVVFPYCLALHF LSLWLVLLYWVWLQDTKFMP NSNGEWLYRVTVALILYF SWFNVSGGRTRGRAT I HLGF I LSD SVLLVTTSWVTD STW-------LPGGVLLWAALGGACF SLGLVL ALF SALFP SYVALHFLGLWLVLLLWVWLQGTDFMPDP S SEWLYRVTVAT I LYF SWFNVAEGRTRGRA I I HFAF LLSDS I LLVATWVTHSSWLP-----SG IP LQLWLPVGCGCFFLGLAL ALFASVVGGFVAVHF LLLWCVFVMWAWLQGTEFMD SVCGEGLYRATVGI IWYF SWFNVAEGQTRGRS I IYHSF I TTDGG ILLLTWWCYRDPVQ-----TEPYGLALLVTLLF SYLLGLLF ALFASVLPCF IF THVFCCWMVFVLFAWRAQTDFMDDPWGERLYRATVALIWYFDWF NVF KKRTKKSALLYHSF I LLD TCMLCGLWFWRMNTHP PQFVIP RPYADVMAS SVVAVY I LGLMV TLF I SVFHLWVALHF LLLWIAF F LWATWQS TDFMRNRI LEHFFRATVAVI LYF SWFNIAD GRT IYRC IVYYCF ITADSVILFMSWK IFKFP S I----- LDEYETYLLYVLAVFFPVGI LF $---340------350---------------------360------370------380------390------400------$ RVIYYLWLHP SCSWD------------------PDLVDGTLGLLSPHR----PPKLIYNRRATLLAENFFAKAKARAVLTEEVQLNGVLRMIYYLRLHP SCSWE------------------PDFVDGTLRLLPPER----PPKLIYNRRATRLAQNFFAKLKTQAALPQAVQLNGVLRLVYYHWLHP SCCWKPD----------------PDQVDGARSLLSPE-----GYQLPQNRRMTHLAQKFFPKAKDEAASPVKG------KTVYYCCF HP TMRRPPA------------- RES SD LPDAEVTFRHF S IQDGAP S SP LLNRRMAAHAARFYSERRAVKNLGGVDAAT S SPP KALYYRFF HP KHNQDNLRGEDQNEVSGQNNDTRRERDE TD GTMMMRMMVSSPAP LRQTQNGKKRMRMLAENFYS-----------------RVLYYLYLHP NLQ------------KKKKKKEMYDEPD GLMSDANGYRLLKREPVMLKNPRI IQLSMQLM--

Fig. S1. An alignment of the amino acid sequences of six vertebrate Xkr8 orthologs. The putative transmembrane regions are shaded blue, perfectly conserved amino acids are red, and the caspase-recognition sites are yellow. 
mouse Xkr8

CED-8

CG32579

mouse $\mathrm{Xkr} 8$

CED-8

CG32579

mouse Xkr8

$$
\text { CED-8 }
$$

CG32579

mouse $\mathrm{Xkr} 8$

CED-8

CG32579

mouse Xkr8

CED-8

CG32579
MPLSVHHHVALDVVVGLVS ILSF LLDLVADLWAVVQYVLLGRYLWAALVLVLLGQASVLLQLF MF LKKHKSKLLLVP PRDEEEDAGIVAVLTDRIPSVVLLVRWFDLFCFGFAMCSYALDFF SDIGIAIFHFWAGRYLSGSLVLAFALLP SVI INII MASAEQRTEVDALMMGP I SKLSMLLTVVS I LWRFVS IC INWS LAYVYWMEES S GYCAWT I GS I LVPMVVTSVI

SWLWLTADP TELHHSQLSRP------------------F LALLHLLQLGYLYRCLHGMHQGLSMCYQEMP SECDLAYADFLSL--DI SMLKLF SMVWMLDD--EMHWKRRAHPRRTGTFELNQKRF IP LSKMIVLCICQMGPLFWYYKALYYGWMFRKS SNENTDGEKRKCF SKMVEAERDATLLRFF Y--------IHTLKSAHA-------GEKRI LERG---VYSNAVI SYLFRDVYVLNYAF KYS LAKERDDKQAE IEYY QKLMTEECNVS FVRLF

ESFLEATPQLTL---VLAIVLQN----GQAEYYQWFGISS---SFLGISWALLDYHRSLRTCLP SKPRLGRSSSAIYFLWNLLLLGPRICAIALF EAFLESAPQLI IQGS IAASYFQNYYQTGTYPYWLYF QAAS LLLS I ISISWSVVVQNRSLRMIRDDKVN IWP HEAVLQFCWRF LT I LARI ITLVAI

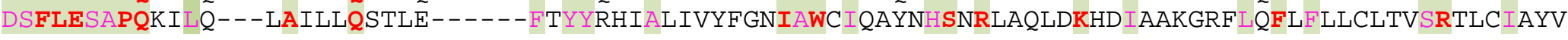

SAVFPYYVA-LHFFSLWLVLLFWIWLOGTNFMPDSKGEWLYRVTMALILYFSWFNVSGGRTRGRAVIHLIFIFSDSVLLVTTSWVTHGTWLPSGI VLIF INVVP I I V VHLLVTLVHVIF LQA I H IDACTH I KLLLI INTF I I IF IP FNMVE GNTRWRYLTAYSVEF I EMMLVCWL----LP LS LNTFP ASIFP IETLI ICATLACFYGTIVFFVD SPMIAKSRP MNYSYCLCFGVVYLF IFTPVKDAPTKYKYAFYLTFCLLONI IACAL---------Y

SLLMWVT IGGACF F LGLALRVIYYLWLHPSCSWDPDLVDGTLGLLSP HRPP KLIYNRRATLLAENFFAKAKARAVLTEEVQLNGVL YIEKVQVGVP ISF IAGIA IMMMYYQF FHP NRRQLIVTQSQEDLS LNVQKSVETLTPKLESSLE I SGEQNTSQDLVSELLLDVEHEN IPLYLATAI IALYIVGIVLLIIYYTYCHPNTVRTYF

Fig. S2. An alignment of amino acid sequences of mouse Xkr8, C. elegans CED-8, and Drosophila CG32579. Identical amino acids are red, and similar amino acids are pink. Similar amino acids are defined as residues belonging to one of the following groups: S, T, P, A, and G; N, D, E, and Q; H, R, and $\mathrm{K} ; \mathrm{M}, \mathrm{I}, \mathrm{L}$ and V; F, Y, and W. Putative transmembrane regions are underlined, and the caspase recognition site in mouse Xkr8 is indicated in green. The number at the end of sequence indicates the number of amino acids of each protein. 
A

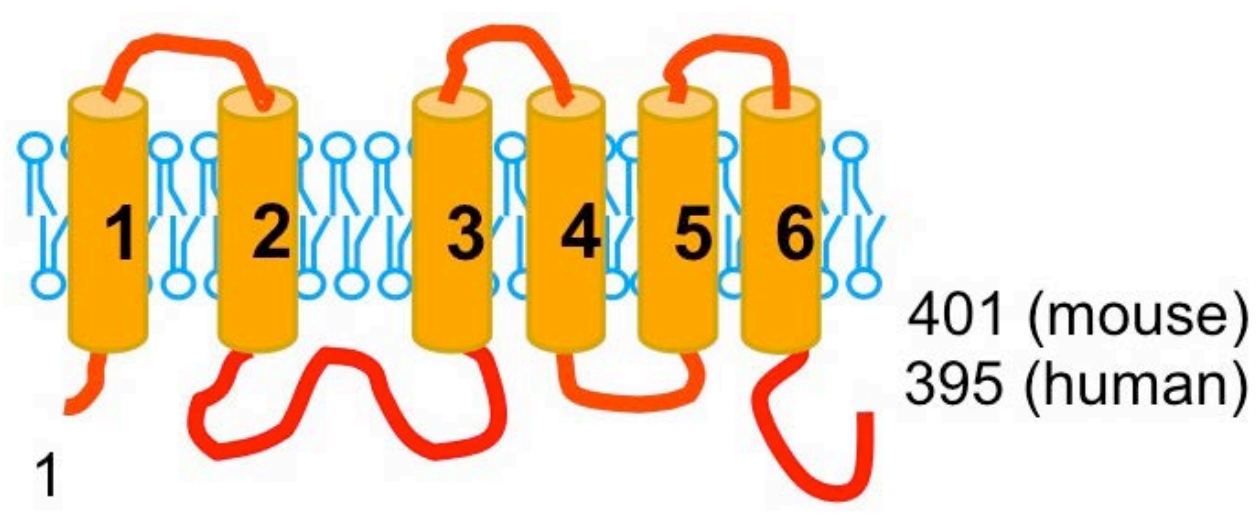

B

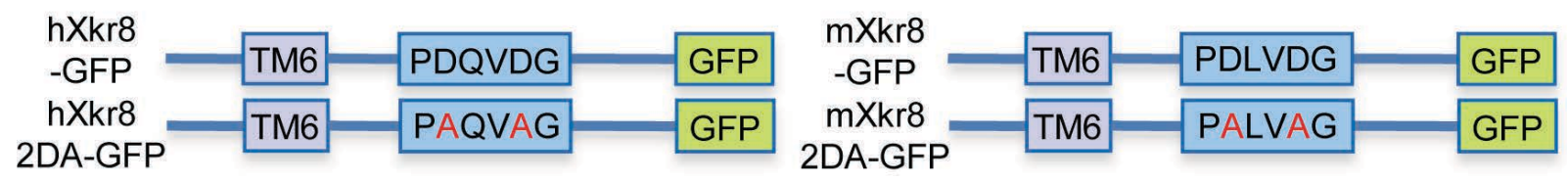

Fig. S3.

Xkr8 and its GFP-fusion proteins. (A) The predicted topology of mammalian Xkr8 proteins. Putative transmembrane regions are numbered. (B) Representations of wild-type and caspaseresistant (2DA) mutant forms of $\mathrm{hXkr8}$ and $\mathrm{mXkr8}$ fused to GFP. TM, transmembrane. 


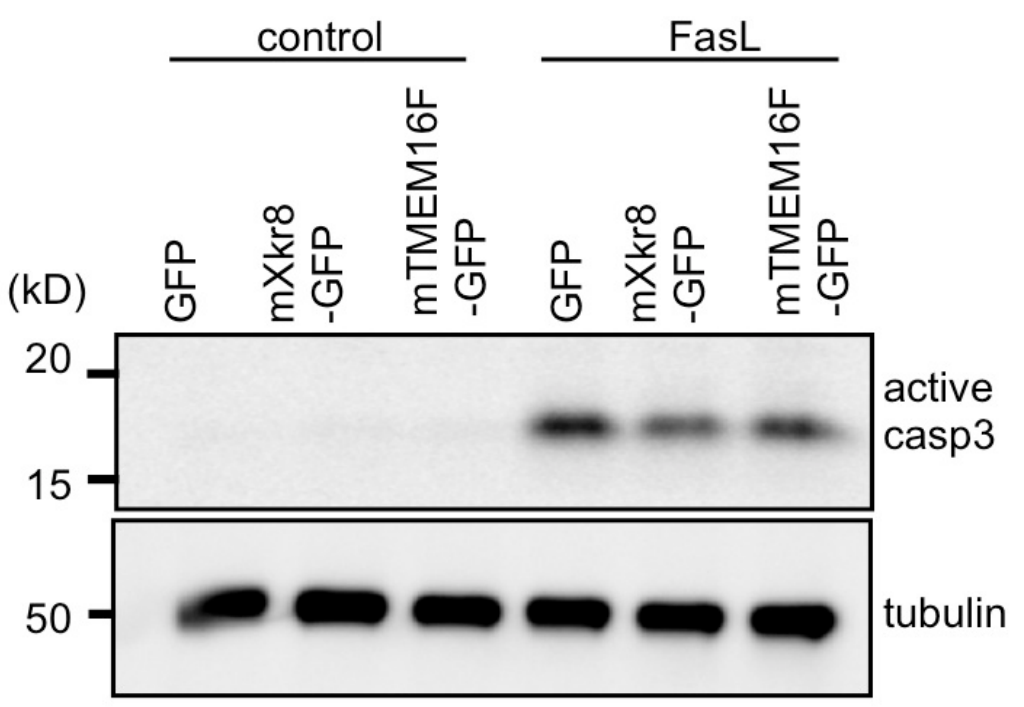

\section{Fig. S4}

FasL-induced activation of caspase-3. WR-Fas transformants expressing GFP, mXkr8-GFP or mTMEM16F-GFP were treated with FasL. The cell lysates were analyzed by western blotting with anti-active caspase- 3 and anti- $\alpha$-tubulin antibodies. 

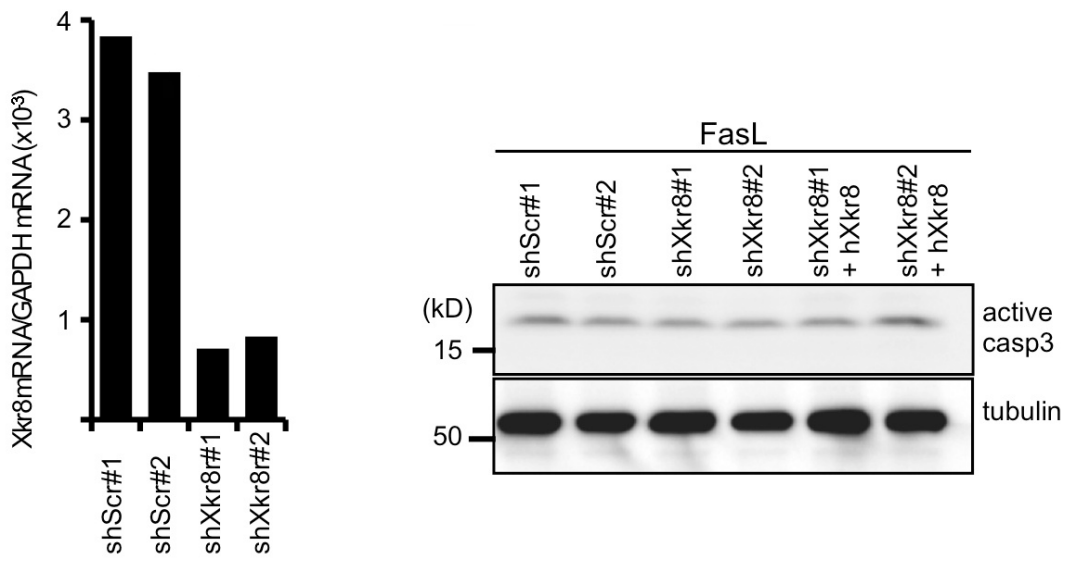

\section{Fig. S5}

Real-time PCR quantification of $\mathrm{mXk} 8 \mathrm{mRNA}$ abundance (relative to GAPDH mRNA) in WR-Fas clones transformed with plasmid DNA carrying $\mathrm{m} X k r 8$ shRNA or scrambled (Scr) shRNA. Two

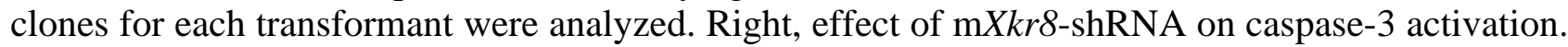
For each WR-Fas transformation (Scr shRNA-expressing, $\mathrm{m} X k r 8$ shRNA-expressing, and $\mathrm{m} X k r 8$ shRNA- plus $\mathrm{h} X k r 8$-expressing transformants), two independent samples were treated with FasL, lysed, analyzed by western blotting with anti-active caspase- 3 and anti- $\alpha$-tubulin antibodies. 
A

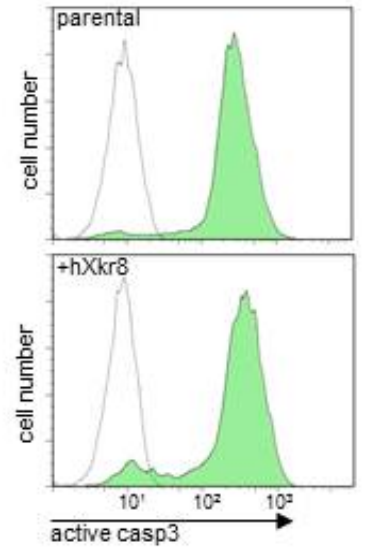

B

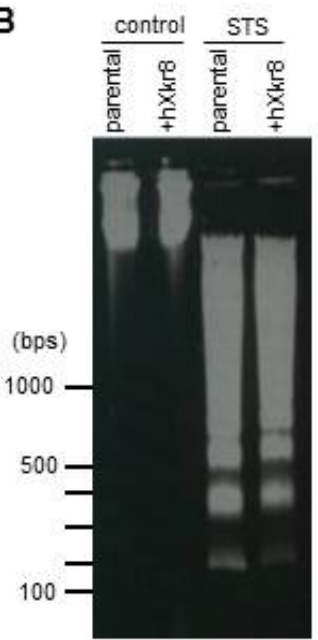

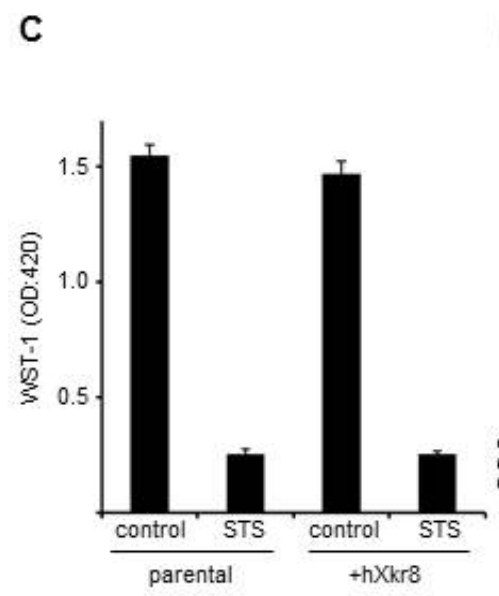

D
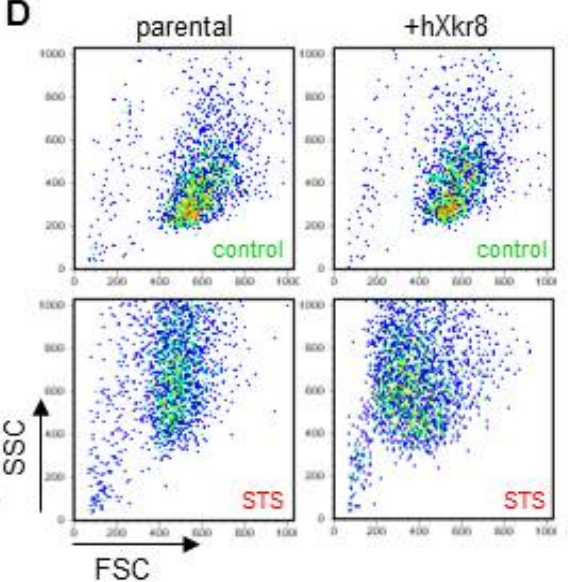

Fig. S6

Xkr8 does not affect most aspects of apoptotic cell death. Human PLB985 cells (parental) and their human Xkr8-transformants $(+\mathrm{hXkr8})$ were treated with $10 \mathrm{mM}$ staurosporine (STS) for $4 \mathrm{hr}$ or left untreated (control). (A) Activation of caspase-3. Paraformaldehyde-fixed cells were permeabilized by treating with methanol and stained with rabbit anti-active caspase-3. The FACS profiles of control and STS-treated cells are represented by green and open areas, respectively. (B) DNA fragmentation. DNA was prepared from control and STS-treated cells, submitted to agarose gel electrophoresis, and stained with ethidium bromide. (C) Cell death. Cell death was assayed by the WST-1 method as described in Materials and Methods. (D) Cell shrinkage. The cells were analyzed by FACSAria. The FSC profiles represent cell size. 
A

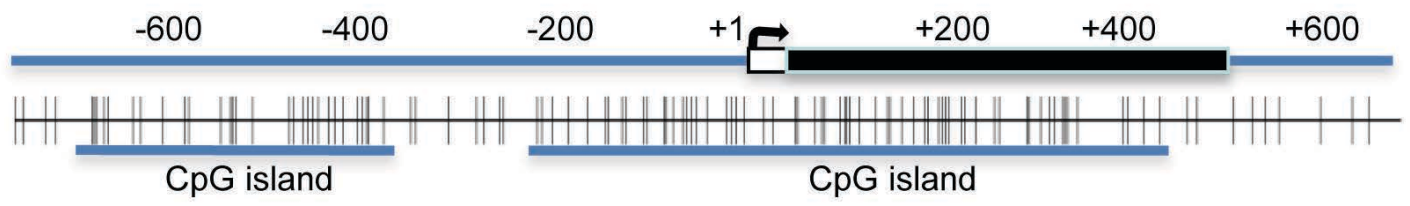

B IRF $\quad-200 \quad$ SP-1 $\quad$ SP-1

SP-1 $S P-1$ GCCTGCGAAGCGAAGGGCAGTCGGTCTTCAGGCCTAGCGGGCTTGGCTGGGCTGGGTCGGTGGACCCCTGGGCTGGCGG

$-150$

$\mathrm{SP}-1$

$\mathrm{SP}-1$

$-100$

$\mathrm{SP}-1$

STAT

CGGGAGCAGAGCATCGAGCGGCTTTTAGCTGGGGTTCGGGCGGAGGACCTGGGACAACCGCGGGCCTCGCTCCTCCCCG

$\mathrm{NF}-\mathrm{kB}$

$\mathrm{SP}-1$

$\mathrm{SP}-1$

$\mathrm{NF}-\mathrm{kB}$

$\mathrm{SP}-1$

$\mathrm{SP}-1$

$+1$

GACGGGGCGGGACGGGGAAGTCCCGCCCACCAGGCCCAGGCCCCGGGCCGCCCCGAGGGCTGCGCCCACCTCCTTCCTG

$\mathrm{C}$

PBL

Jurkat

Namalwa

Raji

PLB985

PLB985 (DAC)

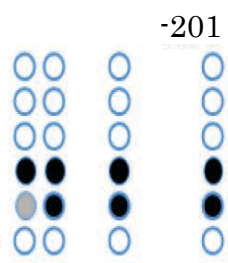

$\begin{array}{cccc}01 & & -151 & \\ 0 & 0 & 0 & 00 \\ 0 & 0 & 00 & 00 \\ 0 & 0 & 0 & 00 \\ 0 & 0 & 00 & 00 \\ 0 & 0 & 00 & 00 \\ 0 & 0 & 0 & 00\end{array}$

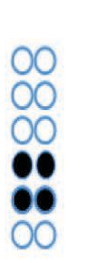

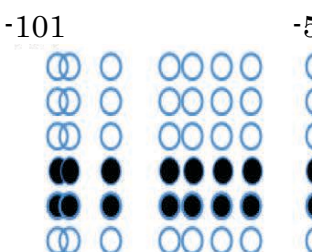

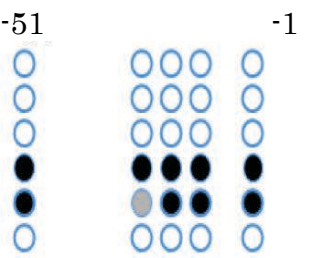

Fig. S7.

Methylation of the $\mathrm{CpG}$ islands in $\mathrm{hXkr8}$ gene. (A) $\mathrm{CpG}$ islands in $\mathrm{hXkr8}$ gene promoter. Open and filled boxes, 5 ' non-coding and coding regions, respectively. Arrow, transcription start site. Each $\mathrm{CpG}$ is represented by a vertical bar. (B) The nucleotide sequence from -232 to +4 of the $\mathrm{h} X k r 8$ gene. The $23 \mathrm{CpGs}$ are shown in red, and predicted transcription-factor recognition sites are underlined. (C) Methylation status of the $\mathrm{CpG}$ islands. Each circle represents a $\mathrm{CpG}$ between positions -232 and +4 , and the extent of methylation is represented by shading: black, 76-100\%; grey, 26-75\%; white, 0-25\%. 
A
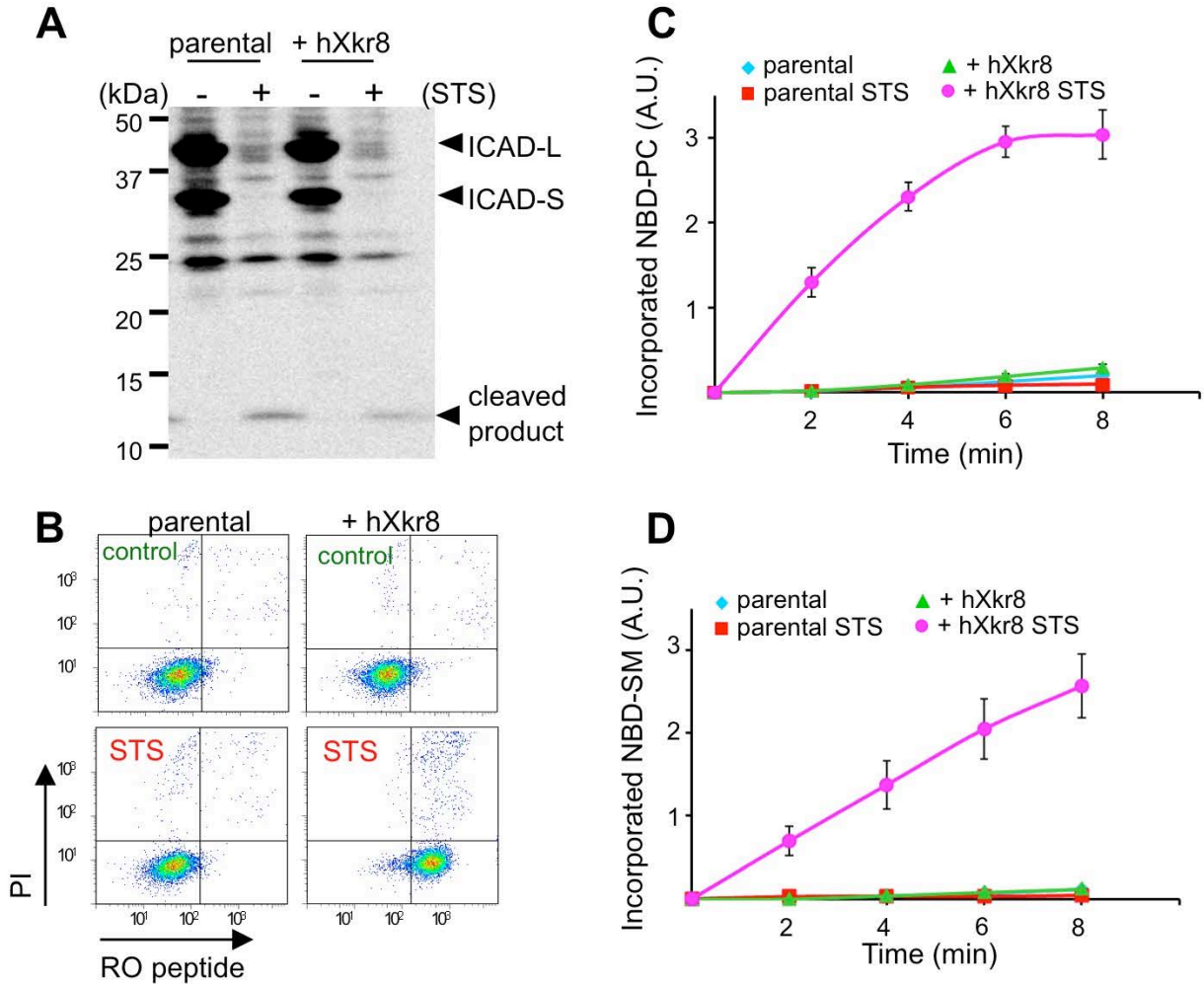

\section{Fig. S8.}

Characterization of the $\mathrm{hXkr8}$-mediated scrambling of phospholipids. (A) Apoptotic cleavage of

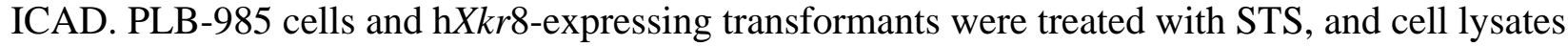
were analyzed by western blotting with anti-ICAD. (B) Apoptotic exposure of PtdEtn. PLB-985 and $\mathrm{h} X k r 8$-expressing transformants were treated with STS, stained with biotin-RO peptide and streptavidin-APC and PI, and analyzed by FACS. (C and D) Scrambling of PtdCho and SM in apoptotic cells. PLB-985 and $\mathrm{hXkr8}$-expressing transformants were treated with STS and incubated with NBD-PC (C) or NBD-SM (D). Unincorporated lipids were extracted and analyzed by FACSAria at two minute time intervals. The fluorescence intensity in the SytoxBlue-negative fraction is shown in arbitrary units as the internalized NBD-PC or NBD-SM. 


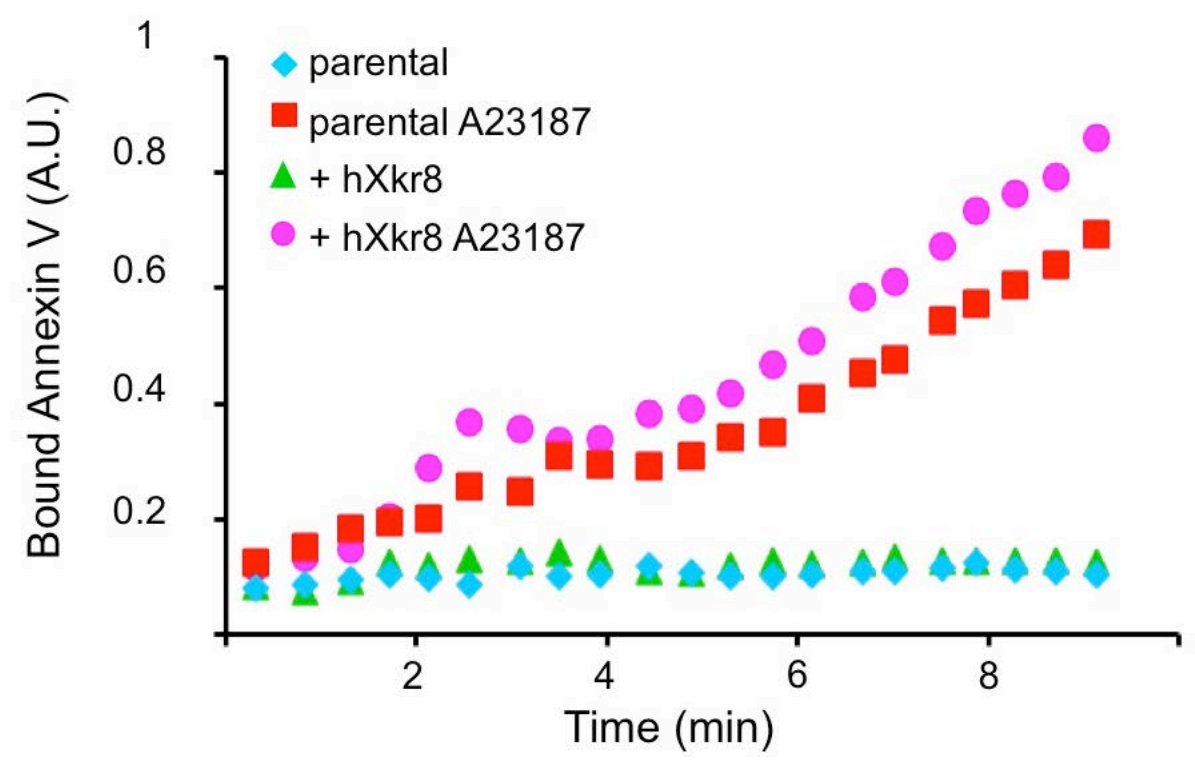

Fig. S9.

$\mathrm{h} X k r 8$ does not alter $\mathrm{Ca}^{2+}$-dependent PtdSer exposure. PLB-985 and its $\mathrm{h} X k r 8$ transformants were treated at $20^{\circ} \mathrm{C}$ with $10 \mu \mathrm{M}$ A23187 and stained with Cy5-labeled Annexin V. Annexin V-binding to the cells was monitored by flow cytometry at two minute intervals for $10 \mathrm{~min}$. 


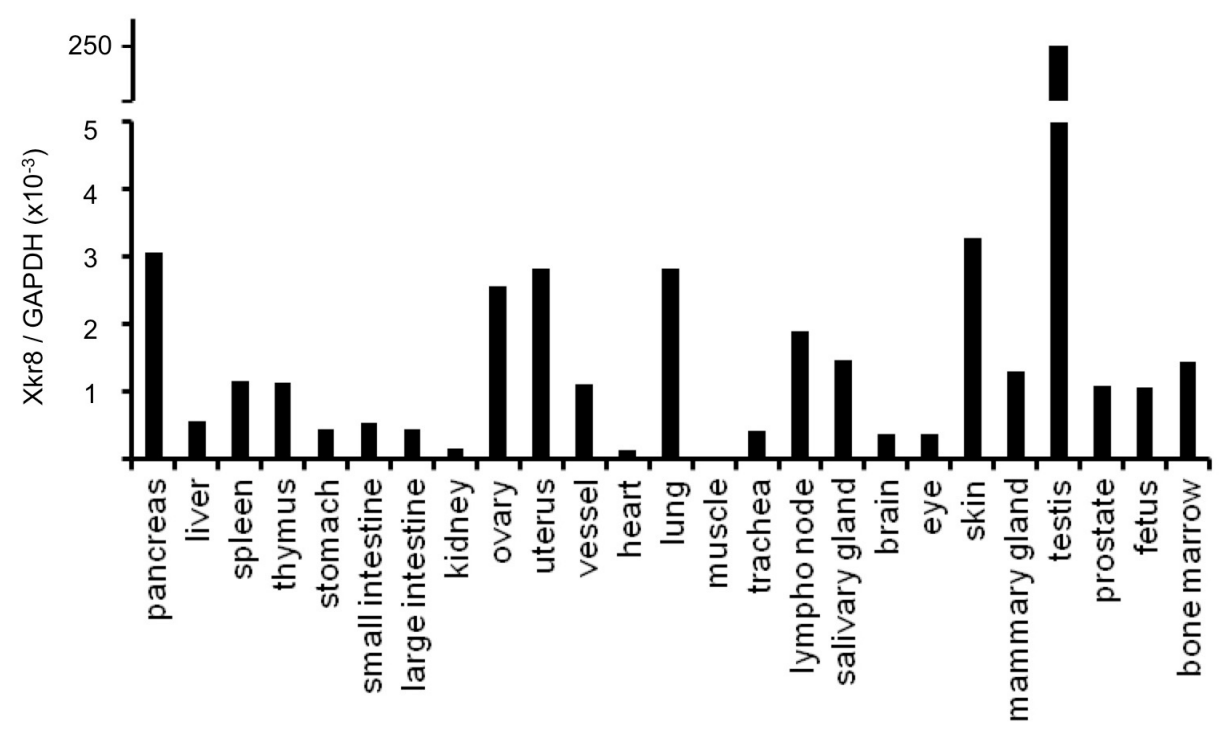

Fig. S10

Xkr8 mRNA abundance in different mouse tissues. Tissue-specific $X k r 8 \mathrm{mRNA}$ levels were determined by real-time RT-PCR and expressed relative to Gapdh mRNA. 


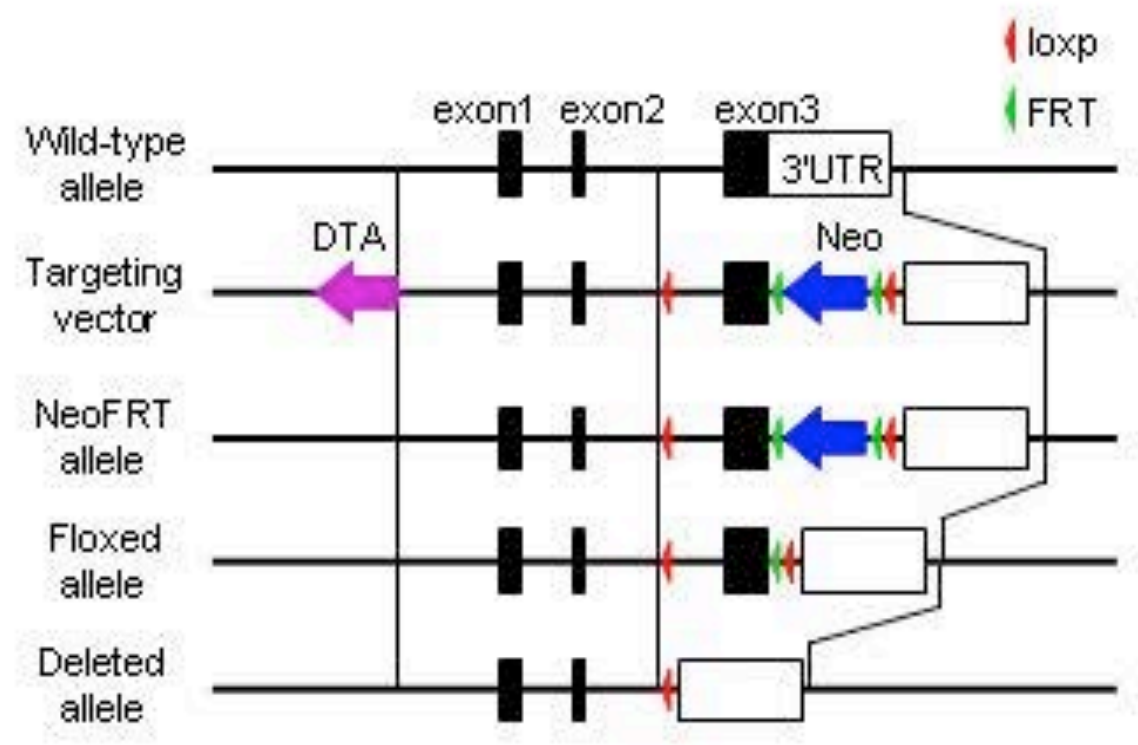

\section{Fig. S11.}

Gene structures of wild-type, floxed and deleted alleles of $\mathrm{mXkr} 8$ and the targeting vector. 
A

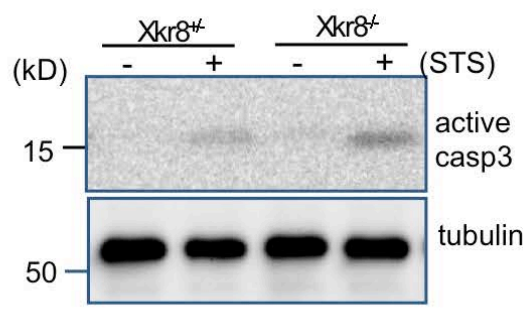

B
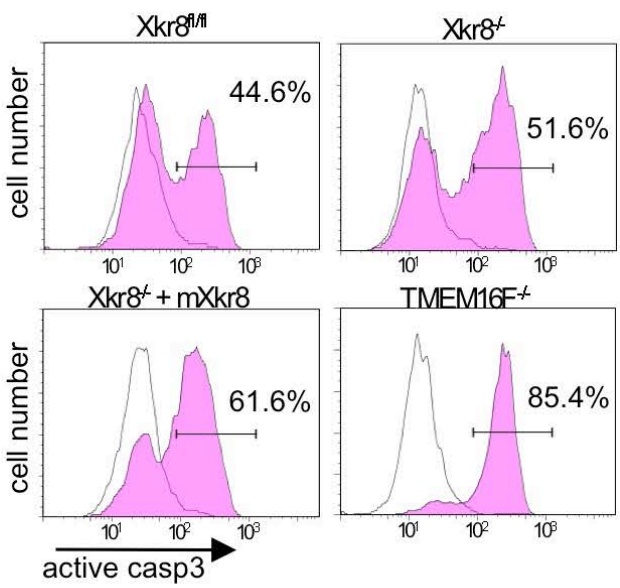

Fig. S12.

$\mathrm{mXkr} 8$ is not required for apoptosis-induced caspase- 3 activation. (A) MEFs from $X k r 8^{+/-}$and $X k r 8^{-}$ - embryos were treated with (+) or without (-) staurosporine (STS) for $8 \mathrm{~h}$. Cell lysates were analyzed by western blotting using anti-active caspase- 3 or anti- $\alpha$-tubulin antibodies. (B) The

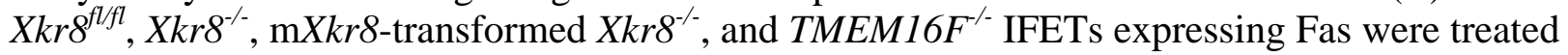
with FasL, stained with anti-active caspase-3, and analyzed with flow cytometry. The FACS profiles for the untreated (open) and FasL-treated cells (filled) are shown. The percentage of cells carrying the active caspase- 3 is indicated. 

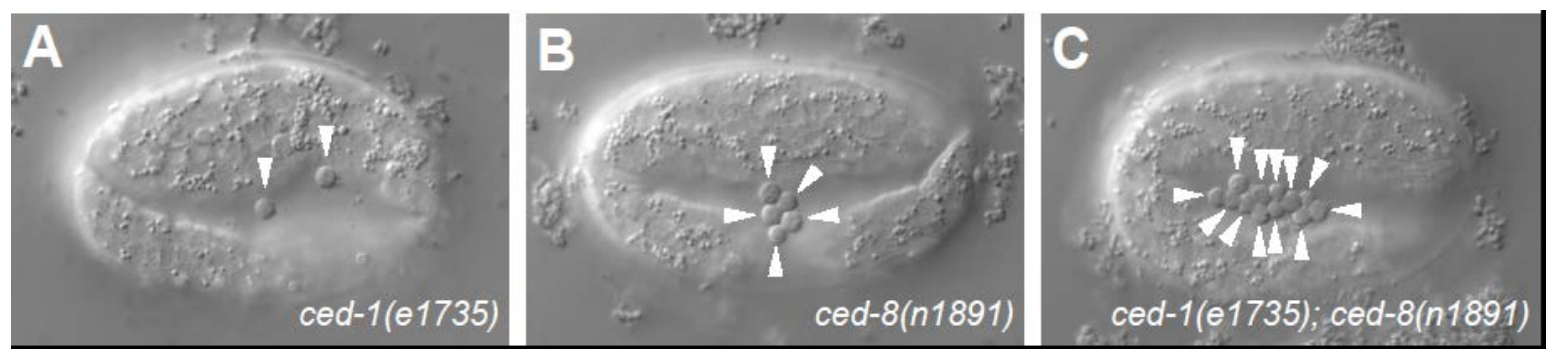

\section{Fig. S13.}

ced-8, the $C$. elegans homolog of mammalian $X k r 8$, promotes the engulfment of apoptotic cells. Shown are Nomarski DIC micrographs of (A) ced-1(e1735), (B) ced-8(n1891), and (C) ced1(e1735); ced-8(n1891) eggs that contain unengulfed apoptotic cells (termed "floaters" and indicated by arrowheads), which have detached from the developing embryo. 


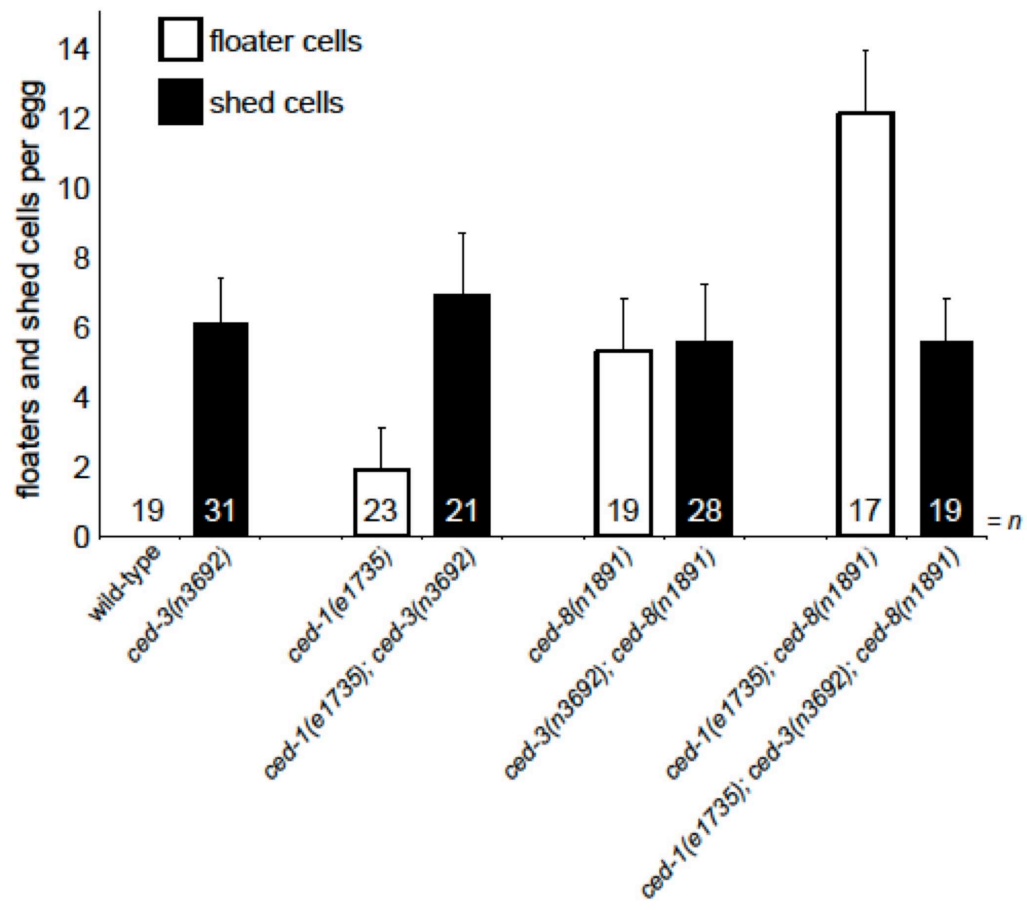

\section{Fig. S14}

The pro-apoptotic caspase CED-3 is required for the generation of floater cells in the eggs of $c e d-8$ mutants and other mutants defective in cell-corpse engulfment. Shown are the combined numbers of embryonic floater and shed cells that were counted in the eggs of each genotype. ced-3 mutations cause the extrusion of shed cells (17). Shed cells are morphologically different from floater cells generated by mutants defective in engulfment. We observed that ced-1 and ced-8 mutations synergistically cause the appearance of floater cells. By contrast, ced-3 mutations caused the appearance of shed cells and suppressed the generation of floaters in all tested genetic backgrounds, including ced-1; ced-8. Thus, ced-3 is epistatic to $c e d-1$ and $c e d-8$ with respect to the generation of shed cells and the suppression of floater cells, indicating that the floater cells of ced-1; ced-8 mutants are dependent on apoptosis. For ease of presentation, we have indicated that ced-3 mutants generate shed cells (black bars) and that ced-1 and ced-8 mutants generate floaters (white bars). Error bars, standard deviations. 

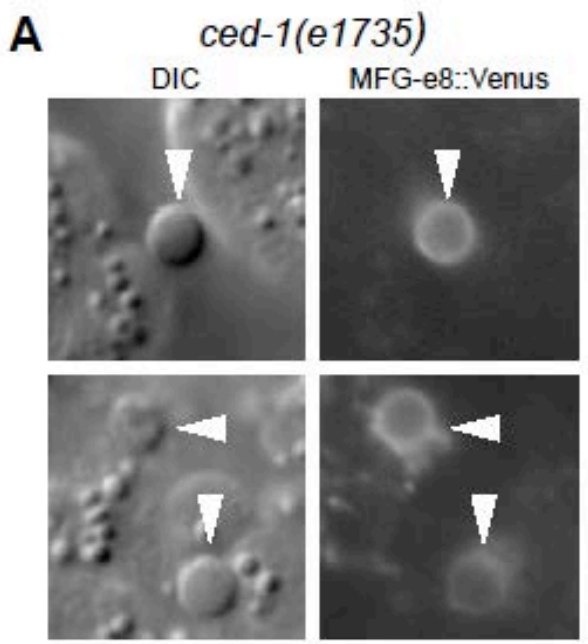

B
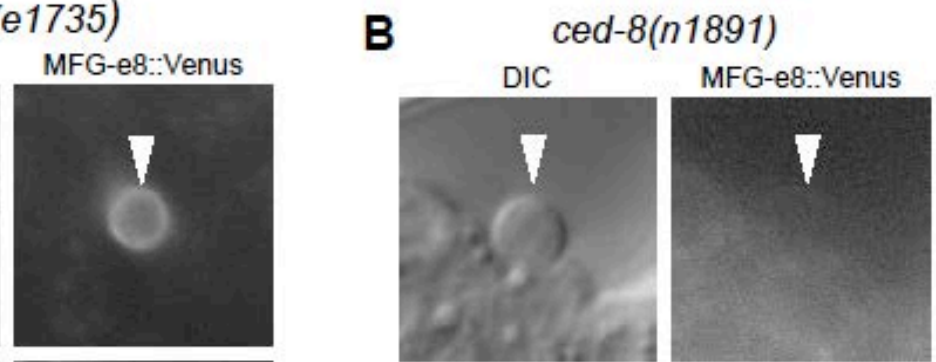

C ced-1(e1735); ced-8(n1891)
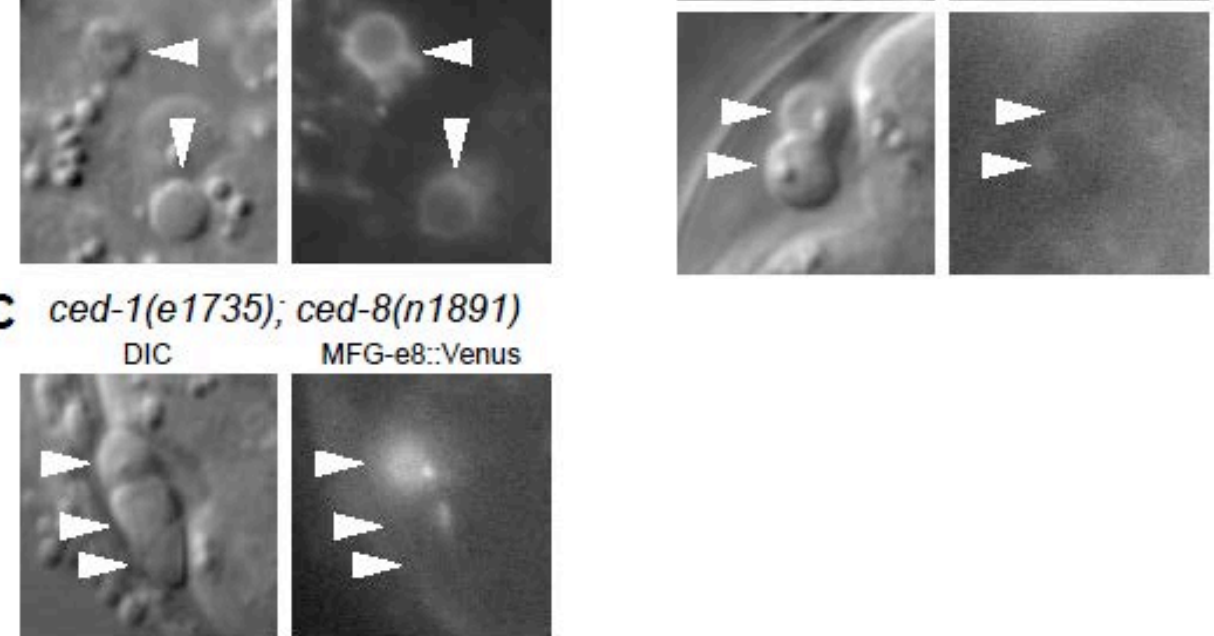

$$
\text { MFG-e8::Venus }
$$
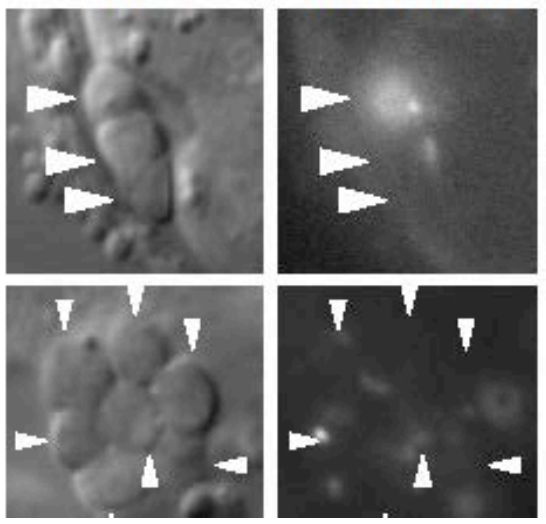

\section{Fig. S15.}

ced-8 promotes PtdSer exposure on the cell surface of floaters, the unengulfed apoptotic cell corpses that detach from engulfment-defective mutant embryos. Shown are Nomarski DIC and fluorescent micrographs of floaters (indicated by arrowheads) generated by $(\boldsymbol{A})$ ced-1(e1735), (B) ced-8(n1891), and (C) ced-1(e1735); ced-8(n1891) mutants. PtdSer was detected using secreted MFG-e8::Venus expressed from the transgene $n I s 398$. All floaters imaged were generated by embryos at the 1.5-fold stage of development or earlier. At later stages of embryonic development, ced-8 mutant floaters exhibit some PtdSer exposure, indicating that ced-8 mutations delay the process of PtdSer exposure and that $C$. elegans contains additional mechanisms of PtdSer exposure. 